\title{
Transferências da União em saúde para o Estado de São Paulo ${ }^{1}$
}

\author{
Marcos Antonio Macedo Cintra \\ e João Carlos Araújo
}

Revista do

Serviço

Público

Ano 52

Número 3

Jul-Set 2001

O modelo de prestação de serviços de saúde no Brasil vem sendo construído nos últimos 15 anos. A Constituição Federal de 1988 instituiu o Sistema Único de Saúde (SUS), que procura consolidar um sistema hierarquizado e descentralizado de serviços de atenção à saúde. Definiu também o financiamento do SUS no âmbito do Orçamento da Seguridade Social da União - que inclui a Previdência, a Saúde e a Assistência Social — tendo as contribuições sociais (calculadas sobre o salário), o faturamento e o lucro das empresas, como a principal fonte de recursos. Como as contribuições sociais são tributos de arrecadação federal, a estratégia de descentralização das ações e da gestão implicava na transferência de recursos da União para os Estados e os municípios. A implementação dessa reforma, ainda em curso, visa, dentre outros propósitos:

a) transferir aos governos estaduais e municipais as funções de gestão e execução dos atos e procedimentos médicos (ambulatoriais e hospitalares) do setor público e privado, restando ao governo federal o financiamento e a normatização dos serviços;

b) transferir aos municípios a maior parte dos atendimentos básicos em saúde; e

c) transferir aos Estados e municípios as atividades de vigilância sanitária e epidemiológica.

Enfim, é a partir dessa concepção, presente na implementação do SUS e enunciada nas suas normas operacionais, que se busca compreender a participação das transferências federais intergovernamentais do setor saúde para o Estado de São Paulo. Este texto procura detalhar a forma de gestão descentralizada das ações do sistema de saúde e as orientações mais recentes de política, que alteraram os mecanismos internos de

\author{
Marcos Antonio \\ Macedo Cintra \\ e João Carlos \\ Araújo são \\ pesquisadores da \\ Diretoria de \\ Economia do \\ Setor Público da \\ Fundação do \\ Desenvolvimento \\ Administrativo \\ do Estado de \\ São Paulo \\ (Fundap). \\ Contatos: \\ macedoci@ \\ uol.com.br \\ jc_araujo@ \\ uol.com.br
}


financiamento e a estrutura de seus programas e seus objetivos. A equação de financiamento do sistema e seus reflexos em transferências para os governos subnacionais são analisados na parte final deste trabalho.

\section{A estrutura organizacional do SUS e as diretrizes recentes do setor}

De acordo com a orientação política estratégica do Ministério da Saúde, as ações do SUS-Municipal, desenvolvidas pelas unidades estatais (próprias, estaduais ou federais) ou privadas (contratadas ou conveniadas, com prioridade para as entidades filantrópicas), precisam estar organizadas e coordenadas de forma que o gestor municipal possa garantir o acesso aos serviços e a disponibilidade de ações e de meios para o atendimento integral. "Isso significa que, independentemente de a gerência dos estabelecimentos prestadores de serviços ser estatal ou privada, a gestão de todo o sistema municipal é, necessariamente, da competência do poder público e exclusiva desta esfera de governo, respeitadas as atribuições do respectivo Conselho e de outras diferentes instâncias de poder". Assim, na Norma Operacional Básica (NOB 01/1996) consta que:

"... gerência é conceituada como sendo a administração de uma unidade ou órgão de saúde (ambulatório, hospital, instituto, fundação etc.) que se caracteriza como prestador de serviços ao Sistema. Por sua vez, gestão é a atividade e a responsabilidade de dirigir um sistema de saúde (municipal, estadual ou nacional), mediante o exercício de funções de coordenação, articulação, negociação, planejamento, acompanhamento, controle, avaliação e auditoria. São, portanto, gestores do SUS os Secretários Municipais e Estaduais de Saúde e o Ministro da Saúde, que representam, respectivamente, os governos municipais, estaduais e federal" (grifos nossos).

O funcionamento desse sistema, apoiado nos municípios, implica em se redefinir os papéis dos gestores estaduais e federais, os quais devem exercer suas competências específicas de gestão e prestar cooperação técnica e financeira aos municípios. "O poder público estadual tem como uma de suas responsabilidades nucleares, mediar a relação entre os sistemas municipais; o federal, de mediar entre os sistemas estaduais. Entretanto, quando ou enquanto um município não assumir a gestão do sistema municipal, é o Estado que responde, provisoriamente, pela gestão de um conjunto de serviços capaz de dar atenção integral àquela população que necessita de um sistema que lhe seja próprio" (op. cit.).

São identificadas quatro funções estratégicas para a gestão no âmbito estadual: 
a) "exercer a gestão do SUS, no âmbito estadual;

b) promover as condições e incentivar o poder municipal para que assuma a gestão da atenção à saúde de seus munícipios, sempre na perspectiva da atenção integral;

c) assumir, em caráter transitório, a gestão da atenção à saúde daquelas populações pertencentes a municípios que ainda não tomaram para si esta responsabilidade; e

d) o mais importante e permanente papel do Estado é promover a harmonização, a integração e a modernização dos sistemas municipais, compondo, assim, o SUS-Estadual".

Por sua vez, cabe ao gestor federal quatro papéis básicos:

a) "exercer a gestão do SUS, em âmbito nacional;

b) promover as condições e incentivar o gestor estadual com vistas ao desenvolvimento dos sistemas municipais, de modo a conformar o SUS-Estadual;

c) fomentar a harmonização, a integração e a modernização dos sistemas estaduais, compondo, assim, o SUS-Nacional;

d) exercer as funções de normatização e de coordenação no que se refere à gestão nacional do SUS."

Assim, do ponto de vista estratégico, compete ao poder público municipal a formulação da política municipal de saúde e a provisão das ações e serviços de saúde. Ao poder público estadual, compete a formulação da política estadual de saúde, a coordenação e o planejamento dos sistemas municipais. Os Estados devem, progressivamente, deixar de ser prestadores de serviços e passar a ter, como atribuição principal, a função de assessorar, apoiar os municípios e articular as políticas regionais. Ao poder público federal, compete a formulação das políticas nacionais, o planejamento, a normatização, a avaliação e o controle do sistema de abrangência nacional.

Dessa forma, o SUS organiza-se como um sistema de comando único por esfera de governo, compreendendo três instâncias de negociação:

a) órgãos gestores (Ministério da Saúde, Secretarias Estaduais de Saúde e Secretarias Municipais de Saúde);

b) comissões de intergestão (Comissão Intergestores Tripartite CIT, de âmbito nacional e Comissão Intergestores Bipartite - CIB, de âmbito estadual); e

c) órgãos de controle social (Conselho Nacional de Saúde - CNS, Conselhos Estaduais de Saúde e Conselhos Municipais de Saúde).

Em meio à evolução dessa estrutura organizacional e de gestão do sistema, a política de saúde desenvolvida pelo governo federal vem, desde o início da década de 90 , progressivamente, enfatizando programas voltados para a atenção básica, ou seja, desenvolver programas que priorizam ações de promoção, proteção e recuperação da saúde dos indivíduos e da família. 
Esse processo foi iniciado em 1991, mediante o Programa de Agentes Comunitários de Saúde (PACS). A partir de 1994, esse processo expandese com a formação das primeiras equipes do Programa da Saúde da Família (PSF), incorporando e ampliando a atuação dos agentes comunitários de saúde.

Essa direção da política nacional de saúde desencadeou mudanças nos mecanismos de financiamento para o setor. O Piso de Atenção Básica (PAB), criado em 1996 e efetivamente implementado em 1998, consolidou uma alteração na lógica do financiamento do SUS. Os recursos deixaram de ser repassados aos municípios por "produção de serviços" e passaram a ser efetuados segundo valores per capita previamente estabelecidos, do Fundo Nacional de Saúde (FNS)2 para os fundos municipais ("transferência fundo a fundo"). Dessa forma, o Secretário Municipal de Saúde passou a exercer, efetivamente, o papel de gestor do SUS em seu município, com a elaboração de planos de ações em saúde de acordo com as especificidades locais. Essa mudança na forma de transferência dos recursos resultou em um impacto redistributivo importante, com um aumento significativo dos recursos destinados aos municípios das regiões Norte e Nordeste.

\section{Legislação, normas operacionais e referenciais da estrutura de repasses}

O conjunto de leis que rege o sistema de saúde no Brasil é formado, fundamentalmente, pela Constituição Federal de 1988, pelas Leis Orgânicas da Saúde (lei no 8.080/1990 e lei no 8.142/1990), pelas NOBs (NOB 01/1993 e NOB 01/1996), pela Instrução Normativa no 01/1998 e por uma gigantesca teia de portarias que regulamenta os programas. ${ }^{3}$ Observa-se, portanto, um processo de normatização crescente dos gastos em saúde nos últimos anos, sobretudo após $1998 .^{4}$

A Constituição instituiu o direito universal e equânime aos serviços e ações de saúde. ${ }^{5}$ Isso significa que ela universalizou o acesso aos serviços de saúde a todos os cidadãos e não apenas aos trabalhadores formalmente inseridos no mercado de trabalho e seus dependentes. Estabeleceu ainda os princípios para a reforma do sistema brasileiro de saúde, por meio da criação do SUS. Segundo o art. 198, "as ações e serviços públicos de saúde integram uma rede regionalizada e hierarquizada e constituem um sistema único, organizado de acordo com as seguintes diretrizes: a) descentralização, com direção única em cada esfera de governo; b) atendimento integral, com prioridade para as atividades preventivas, sem prejuízo dos serviços assistenciais; c) participação da comunidade". Assim, incorporou de forma explícita a descentralização da gestão do sistema; a 
integralidade da atenção à saúde, efetivada por meio de ações de promoção, prevenção, cura e reabilitação; e reconheceu o direito e a necessidade da participação da comunidade na gestão do sistema, mediante os Conselhos de Saúde.

Ao longo dos últimos anos, foi ocorrendo, então, a unificação da redes federal, estadual e municipal de saúde em um único sistema, estabelecendo a gestão descentralizada das ações e serviços de saúde, com comando único. Promoveu-se, ainda, a incorporação do Instituto Nacional de Assistência Médica da Previdência Social (Inamps), vinculado ao Ministério da Previdência e Assistência Social (MPAS) e responsável pela assistência ambulatorial e hospitalar dos segurados, ao Ministério da Saúde, que ficou encarregado de prestar assistência integral a toda a população. A atuação da Previdência ficou restrita ao gerenciamento dos benefícios de auxílio e aposentadoria.

A lei no 8.080, de 19 de setembro de 1990, regulamentou o SUS e agregou todos os serviços estatais — das três esferas: federal, estadual e municipal - e os serviços privados (desde que contratados ou conveniados). De acordo com essa legislação, ao SUS compete prestar assistência às pessoas por intermédio de ações de promoção, proteção e recuperação da saúde, com a realização integrada das ações assistenciais e das atividades preventivas, inclusive as ações de vigilância sanitária, vigilância epidemiológica, saúde do trabalhador, e assistência terapêutica integral, inclusive farmacêutica.

A lei no 8.142, de 28 de dezembro de 1990, dispôs sobre a participação da comunidade na gestão do SUS — Conferência de Saúde, Conselhos Nacional, Estaduais e Municipais de Saúde, Conselho Nacional de Secretários Estaduais de Saúde, o Conselho Nacional de Secretários Municipais de Saúde, Fundo de Saúde, Plano de Saúde etc. — e regulamentou a forma e condições para as transferências intergovernamentais de recursos.

A NOB 01/1993 introduziu um modelo institucional do processo de descentralização e de responsabilidades das diferentes instâncias governamentais em relação à saúde. Normatizou, portanto, as relações intergovernamentais, criando regras de transferências de recursos, mecanismos de controle e de avaliação. No que se refere aos mecanismos de repasse, a cooperação financeira do Ministério da Saúde para custeio da Assistência Hospitalar e Ambulatorial, das Ações de Vigilância Sanitária, das Ações de Epidemiologia e de Controle de Doenças, com os órgãos ou entidades federais, estaduais e do Distrito Federal, prefeituras municipais, instituições de assistência à saúde e educacionais, filantrópicas ou não e organizações não-governamentais (ONGs), passou a se dar mediante:

a) transferência, de forma regular e automática, de recursos do FNS aos municípios, Estados e Distrito Federal, independentemente de convênio ou instrumento congênere; 
b) remuneração por serviços produzidos, que consiste no pagamento direto aos prestadores estatais ou privados contratados e conveniados, contra a apresentação de faturas, referentes a serviços realizados conforme programação e mediante prévia aprovação do gestor, segundo valores fixados em tabelas editadas pela Secretaria de Assistência à Saúde do Ministério da Saúde; e

c) repasse por meio da celebração de convênios ou instrumentos similares com órgãos ou entidades federais, estaduais e do Distrito Federal, prefeituras municipais e ONGs, interessados em financiamentos de projetos específicos na área da saúde (ver Figura 1). ${ }^{6}$

\section{Figura 1}

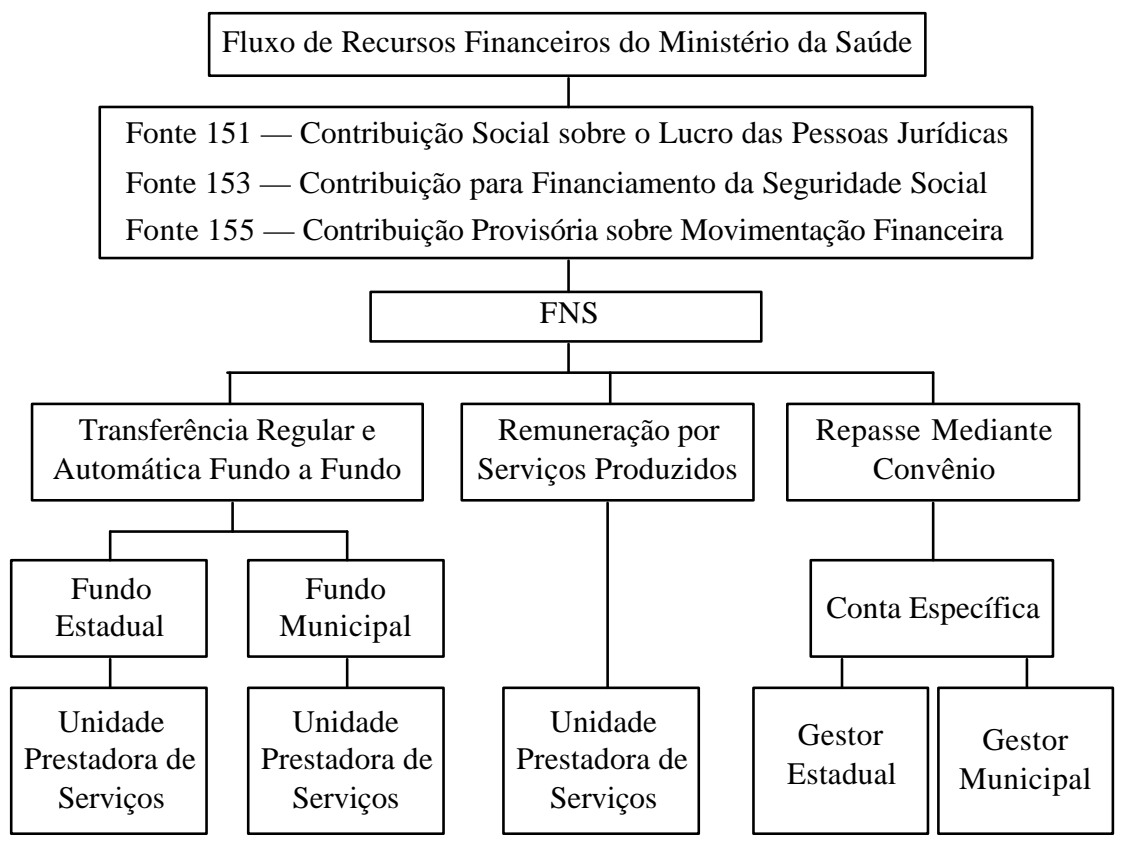

Definiu-se, ainda, uma escala de habilitação para Estados e municípios - gestão incipiente, parcial ou semiplena — de acordo com as responsabilidades assumidas e as formas de repasses de recursos correspondentes.

A NOB 01/1996 ampliou a responsabilidade dos gestores municipais e estaduais e induziu mudanças no modelo assistencial, fortalecendo a atenção básica de saúde e as ações de saúde coletiva. A partir dessa NOB, os municípios passaram a ter maior autonomia para gerir os recursos da saúde, reduzindo progressiva e continuamente a remuneração por produção de serviços e ampliando as transferências de caráter global, do FNS para os Fundos Municipais e Estaduais de Saúde, com base em programações 
ascendentes, pactuadas e integradas. Isso implicou no aperfeiçoamento da gestão dos serviços de saúde e na própria organização do sistema, uma vez que o município passou a ser, de fato, o responsável imediato pelo atendimento das necessidades e demandas de saúde e exigências de intervenções.

Foi criado o PAB, um montante de recursos financeiros destinados exclusivamente ao custeio de procedimentos e ações de atenção básica à saúde pelos municípios. As transferências do PAB aos Estados correspondem apenas ao valor para cobertura da população residente em municípios ainda não habilitados na forma da NOB 01/96. Mediante a portaria no 1.882/GM, do Ministério da Saúde, de 18 de dezembro de 1997, definiu-se que o PAB é composto de uma parte fixa destinada à assistência básica e de uma parte variável relativa a incentivos para o desenvolvimento de ações no campo específico da atenção básica.

A parte fixa do $\mathrm{PAB}$, destinada à assistência básica, é obtida pela multiplicação de um valor per capita nacional pela população de cada município. As ações custeadas com recursos destinados à assistência básica são:

a) consultas médicas em especialidades básicas;

b) atendimento odontológico básico (procedimentos coletivos, procedimentos individuais preventivos, dentística e odontologia cirúrgica básica);

c) atendimentos básicos por outros profissionais de nível superior;

d) visita/atendimento ambulatorial e domiciliar por membros da equipe de saúde da família;

e) vacinação;

f) atividades educativas a grupos da comunidade;

g) assistência pré-natal;

h) atividades de planejamento familiar;

i) pequenas cirurgias;

j) atendimentos básicos por profissional de nível médio;

k) atividades dos agentes comunitários de saúde;

1) orientação nutricional e alimentar, ambulatorial e comunitária;

m) assistência ao parto domiciliar por médico do PSF; e

n) pronto atendimento.

A parte variável do PAB destina-se a incentivos às ações básicas de Vigilância Sanitária, Vigilância Epidemiológica e Ambiental, à Assistência Farmacêutica Básica, aos PACS, PSFs, aos Programas de Combate às Carências Nutricionais, e outros que venham a ser posteriormente agregados, e será definida com base em critérios técnicos específicos de cada programa.

O PACS e o PSF destinam-se a estimular a implementação de agentes comunitários de saúde e equipes de saúde da família, no âmbito municipal, reorientando práticas, com ênfase nas ações de prevenção de 
doenças e promoção da saúde, em substituição ao modelo tradicional de assistência, orientado para a cura de doenças, geralmente em hospitais. Procuram, portanto, ampliar o acesso da população aos serviços básicos de saúde, tendo as equipes de saúde da família como eixo estruturante. Torna-se fundamental o apoio da própria população, com a figura do agente comunitário de saúde, pois esses programas são destinados a pequenas cidades com escassez de serviços e de profissionais de saúde.

A concepção dos programas foi estruturada da seguinte forma: na cidade onde o projeto for implementado, procura-se levantar o número de casas e/ou famílias. De acordo com a concentração da população, agrupamse de 150 a 250 famílias. Dentre seus habitantes, seleciona-se uma pessoa que more no local há pelo menos dois anos para ser treinada como agente comunitário de saúde. Esse indivíduo passará a visitar as famílias, pelo menos uma vez por mês; deverá cadastrar todos moradores, verificar as doenças existentes, identificar as gestantes e observar se estão realizando o pré-natal, controlar a caderneta de vacinação das crianças, ensinar medidas higiênicas etc. A cada cinco agentes comunitários agrega-se uma equipe de saúde da família constituída de um médico, uma enfermeira e uma auxiliar de enfermagem. Os membros da equipe não precisam morar na área onde atuam, mas, obrigatoriamente, têm de trabalhar em tempo integral no posto e visitar as casas indicadas pelos agentes. Para cada 20 equipes de saúde da família instala-se um ambulatório com 12 especialidades, incluindo Odontologia e Saúde Mental. Os hospitais funcionam como referência nos casos que necessitarem de internação.

Assim, a estratégia desses programas foi estruturada a partir dos agentes comunitários e das unidades de saúde da família — uma unidade pública de saúde, com equipe multidisciplinar que assume a responsabilidade por uma determinada população, desenvolvendo ações de promoção e prevenção em saúde, tratamento e reabilitação. ${ }^{7}$

Ficou estabelecido um acréscimo percentual ao montante do PAB, de acordo com os critérios a seguir relacionados, sempre que equipes de saúde da família, agentes comunitários de saúde, ou estratégias semelhantes de garantia da integralidade da assistência estiverem atuando de forma integrada à rede municipal.

O PSF representa:

a) acréscimo de $3 \%$ sobre o valor do PAB para cada $5 \%$ da população coberta, até se atingir $60 \%$ da população total do município;

b) acréscimo de 5\% sobre o valor do PAB para cada 5\% da população coberta, quando estiver atendendo entre $60 \%$ e $90 \%$ da população total do município; e

c) acréscimo de $7 \%$ sobre o valor do PAB para cada $5 \%$ da população coberta, quando estiver atendendo entre $90 \%$ e $100 \%$ da população do município. 
Esses acréscimos têm, como limite, $80 \%$ do valor do PAB do município. São repassados R $\$ 28.000,00 /$ ano para cada equipe instalada, destinados ao pagamento de salários e encargos dos profissionais específicos para o desenvolvimento do programa.

O PACS representa:

a) acréscimo de $1 \%$ sobre o valor do PAB para cada 5\% da população coberta, até se atingir $60 \%$ da população total do município;

b) acréscimo de $2 \%$ sobre o valor do PAB para cada 5\% da população coberta, quando estiver atendendo entre $60 \%$ e $90 \%$ da população total do município; e

c) acréscimo de $3 \%$ sobre o valor do PAB para cada $5 \%$ da população coberta, quando estiver atendendo entre $90 \%$ e $100 \%$ da população do município.

Esses acréscimos têm, como limite, $30 \%$ do valor do PAB do município. São repassados R \$2.200,00/ano para cada agente comunitário de saúde, destinados ao pagamento de salários e encargos dos profissionais específicos para o desenvolvimento do programa. ${ }^{8}$

A Assistência Farmacêutica Básica destina-se exclusivamente à aquisição de medicamentos básicos essenciais, dispensados na rede ambulatorial do SUS sob prescrição médica, contribuindo para a garantia da integralidade na prestação da assistência básica à saúde. Esse programa é financiado pelos três gestores. A transferência dos recursos federais fica condicionada à contrapartida dos Estados, municípios e do Distrito Federal. O Ministério da Saúde, por meio da Secretaria Executiva, repassa os recursos federais aos Estados e municípios qualificados, correspondentes a 1/12 (um doze avos) do valor final do incentivo, na proporção do número de habitantes dos municípios.

Além disso, todo Estado deve elaborar o Plano Estadual de Assistência Farmacêutica Básica que deve conter:

a) o elenco de medicamentos para assistência básica, aprovado pela CIB;

b) os mecanismos de adesão e responsabilidade dos municípios, para integrarem o Plano Estadual de Assistência Farmacêutica Básica;

c) o pacto de gestão entre o Estado e o município, negociado na $\mathrm{CIB}$, incluindo a contrapartida de recursos do Estado e municípios, com a respectiva ata de aprovação;

d) a sistemática de programação, acompanhamento, controle e avaliação da implementação do Plano no Estado.

O Programa de Combate às Carências Nutricionais destina-se ao desenvolvimento de ações de nutrição e alimentação a grupos populacionais determinados, em áreas endêmicas de má nutrição, visando combater a desnutrição e proteger o estado nutricional. Os recursos destinam-se à aquisição de leite integral e óleo de soja. O custo previsto para a 
recuperação nutricional foi fixado em $\mathrm{R} \$ 180,00$ por criança/ano, calculado com base no número estimado de crianças em risco nutricional, com idade entre 6 e 23 meses. O valor desses recursos direcionado a cada município corresponde a um máximo de $50 \%$ dos custos para as atividades de recuperação nutricional, que inclui, prioritariamente, $\mathrm{o}$ aleitamento materno e o combate às deficiências de ferro (gestantes e crianças) e de vitamina A (menores de cinco anos).

As Ações Básicas de Vigilância Sanitária destinam-se ao incremento de ações básicas de fiscalização e controle sanitário em produtos, serviços e ambientes sujeitos à vigilância sanitária, bem como às atividades de educação em vigilância sanitária. Incluem, por exemplo, inspeção sanitária em piscina de uso público e restrito, terreno baldio, canteiro de obra, hotéis, motéis e congêneres, cemitério/necrotério e crematório, dispensário de medicamentos etc. Trata-se, portanto, de um Piso Básico de Vigilância Sanitária (PBVS) — R \$ 0,25/habitante ano — para custear ações básicas de vigilância sanitária executadas por municípios (em gestão plena da atenção básica ou Estados em gestão avançada). ${ }^{9}$

As Ações Básicas de Vigilância Epidemiológica e Ambiental destinamse às ações básicas de investigação epidemiológica e ambiental, de diagnóstico de situações epidemiológicas e ambientais de risco, e de ações de controle, eliminação e erradicação de agentes de agravos e danos à saúde individual e coletiva das populações.

A implementação desses programas expressa a opção por novos mecanismos de financiamento que privilegiam a descentralização de recursos com a adoção de valor per capita nacional. A elaboração e a implementação de políticas de saúde no âmbito municipal podem permitir não só maior eficácia das ações, mas também maiores possibilidades de controle social. Tais iniciativas podem contribuir para o desenvolvimento de um sistema de saúde mais eqüitativo e eficiente, baseado na prevenção das doenças e na promoção da saúde.

A fim de reordenar os mecanismos e fluxos de financiamento, a NOB 01/1996 estabeleceu, ainda, os Tetos Financeiros dos Recursos Federais para municípios, Estados e Distrito Federal, constituídos pela soma dos Tetos Financeiros da Assistência (TFA), da Vigilância Sanitária (TFVS) e da Epidemiologia e Controle de Doenças (TFECD). ${ }^{10}$ Assim, os recursos de custeio da esfera federal, destinados às ações e serviços de saúde, configuram o Teto Financeiro Global (TFG), cujo valor, para cada Estado e município, é definido com base na Programação Pactuada e Integrada (PPI). O teto financeiro do Estado contém os tetos de todos os municípios, habilitados ou não para qualquer uma das condições de gestão.

Os tetos financeiros passaram a ser o núcleo do SUS, com o Ministério da Saúde promovendo o detalhamento de todos os procedimentos 
ambulatoriais (mais de 2000) e incorporando as ações de vigilância sanitária e de epidemiologia e controle de doenças da Fundação Nacional de Saúde (Funasa). O sistema foi organizado em três níveis de complexidade (atenção básica, média e alta complexidade) distribuídos em oito blocos, quais sejam:

Procedimentos Básicos:

Bloco 1 - Procedimentos Assistenciais Básicos em Saúde;

Bloco 2 - Procedimentos Básicos em Vigilância Sanitária;

Bloco 3 - Procedimentos Básicos em Epidemiologia e Controle de Doenças;

Procedimentos de Média Complexidade:

Bloco 4 - Procedimentos Assistenciais de Média Complexidade;

Bloco 5 - Procedimentos de Média Complexidade em Vigilância Sanitária;

Bloco 6 - Procedimentos de Média Complexidade em Epidemiologia e Controle de Doenças;

Procedimentos de Alta Complexidade:

Bloco 7 - Procedimentos Assistenciais de Alta Complexidade;

Bloco 8 - Procedimentos de Alta Complexidade em Vigilância Sanitária.

Assim, os atendimentos ambulatoriais básicos passaram a ser remunerados por valores per capita, por meio do PAB, e foram desagregados do fluxo de pagamentos do sistema. Os procedimentos de média complexidade foram mantidos na lógica do Sistema de Informações Ambulatoriais (SIA), e aqueles de alta complexidade (hemodiálise, químio/ radioterapia) foram destacados em um sistema de registro chamado de Autorização de Procedimentos de Alta Complexidade, que identifica os usuários e individualiza os registros.

A NOB 01/1996 simplificou também o processo de habilitação de Estados e municípios, que ficou reduzido à Gestão Plena da Atenção Básica e Gestão Plena do Sistema Municipal, para o caso dos municípios e, Gestão Avançada do Sistema Estadual e Gestão Plena do Sistema Estadual, para o caso dos Estados (ver Figuras 2 e 3 ).

Finalmente, a Instrução Normativa no 01, de 2 de janeiro de 1998, do Ministério da Saúde, regulamentou os conteúdos, instrumentos e fluxos do processo de habilitação de municípios, de Estados e do Distrito Federal às novas condições de gestão criadas pela NOB 01/1996. Vale dizer, essa Instrução Normativa operacionalizou o processo de habilitação de municípios e Estados às condições de gestão estabelecidas na NOB 01/1996, a fim de aprofundar a descentralização da gestão no âmbito do SUS. 


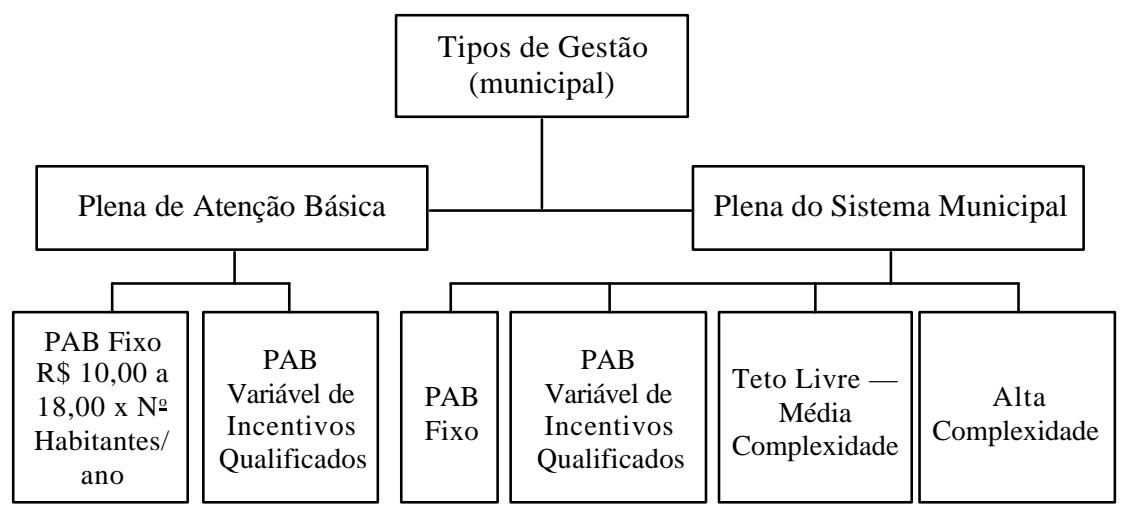

Figura 3

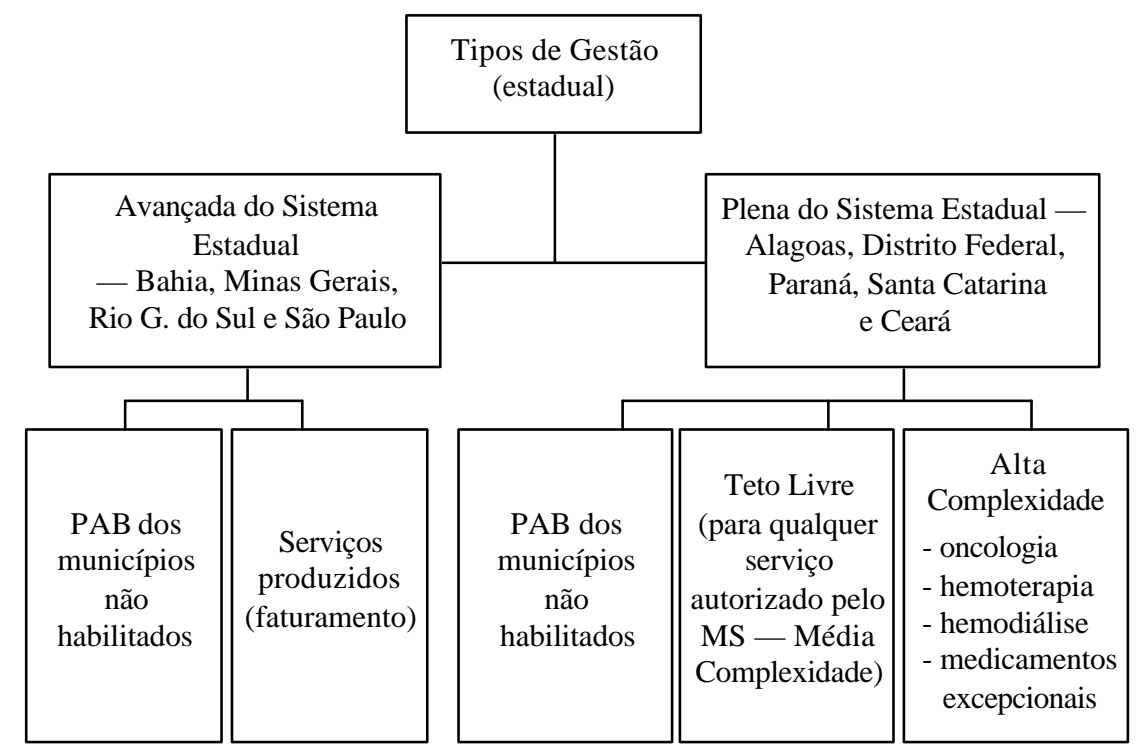

Os municípios sob Gestão Plena da Atenção Básica passaram a ter responsabilidade plena pelas ações de atenção básica, incluindo a gestão das unidades prestadoras públicas e o controle e pagamento dos serviços das unidades contratadas, conveniadas e externas ao município. A Gestão Plena de Atenção Básica engloba uma série de procedimentos de caráter ambulatorial - clínica médica, ginecologia, obstetrícia, pediatria e pequenas cirurgias ambulatórias - , bem como ações de alcance coletivo (ações básicas de vigilância sanitária). Para as ações relacionadas à atenção básica em saúde o repasse dos recursos ocorre mediante transferência regular e automática. Porém, as internações hospitalares e ambulatoriais especializadas continuaram sendo pagas pela Secretaria Estadual de Saúde ou pelo Ministério de Saúde — de acordo com a condição de gestão estadual 
- e o papel da Secretaria Municipal restringe-se a cadastrar os prestadores e autorizar os serviços. O município assumiria, portanto, plenamente a gestão das unidades básicas de saúde, sejam estatais, sejam privadas, mas os serviços mais complexos permaneceriam sendo prestados segundo a lógica da produção de serviços (Arretche e Marques, 2000: 17).

Assim, para os municípios habilitados à condição de Gestão Plena da Atenção Básica foi definido o TFG do município, relativo aos recursos de custeio da esfera federal, discriminando os recursos pagos por prestação de serviços e a parcela a ser transferida de forma regular e automática, fundo a fundo, incluindo os programas de assistência ambulatorial e hospitalar, vigilância sanitária e epidemiologia e controle de doenças (ver Figuras 4 e 5): ${ }^{11}$

I - Teto Financeiro para a Assistência do Município (TFAM), discriminando o que comporá o teto do município, nas parcelas abaixo:

a) de atenção hospitalar com especificação dos valores relativos à Autorização de Internação Hospitalar (AIH), ao Fator de Incentivo ao Desenvolvimento do Ensino e Pesquisa (Fideps) e ao Índice de Valorização Hospitalar de Emergência (IVH-E); ${ }^{12}$

b) de atenção ambulatorial com especificação dos valores relativos à assistência básica - parte fixa do PAB, à Fração Assistencial Especializada (FAE) ${ }_{13}^{13} \mathrm{e}$ à Remuneração de Procedimentos de Alto Custo/Alta Complexidade, ${ }^{14} \mathrm{e}$

c) dos incentivos do PAB — parte variável, com especificação dos valores relativos ao PACS, PSF, à Assistência Farmacêutica Básica, ao Programa de Combate às Carências Nutricionais, às Ações Básicas de Vigilância Sanitária e às Ações Básicas de Vigilância Epidemiológica e Ambiental.

II - TFVS, compreendendo:

a) ações de média e de alta complexidade em vigilância sanitária: ${ }^{15} \mathrm{e}$

b) recursos do Programa Desconcentrado de Ações de Vigilância Sanitária (PDAVS) ${ }^{16}$

\section{III - TFECD.}

Portanto, para desempenhar suas funções, a administração municipal recebe do Ministério da Saúde recursos derivados de transferências regulares e automáticas, o PAB, fixo e variável, o PBVS, e os recursos correspondentes às ações e epidemiologia e de controle de doenças. As internações hospitalares e os procedimentos hospitalares de alto custo são pagos diretamente pelo gestor nacional ou estadual, com base na fatura de serviços produzidos e aprovados, bem como nos valores estabelecidos pelo SUS (ver Figura 6). 


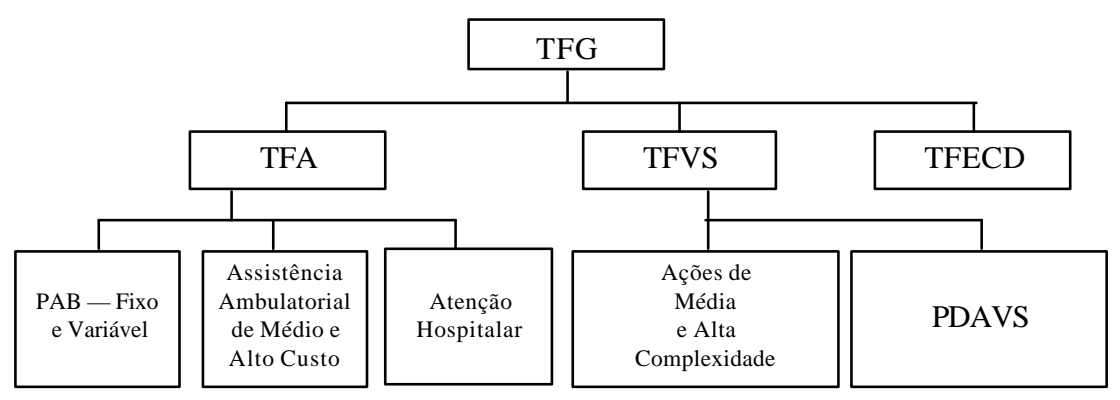

\section{Figura 5}

\section{TFA}

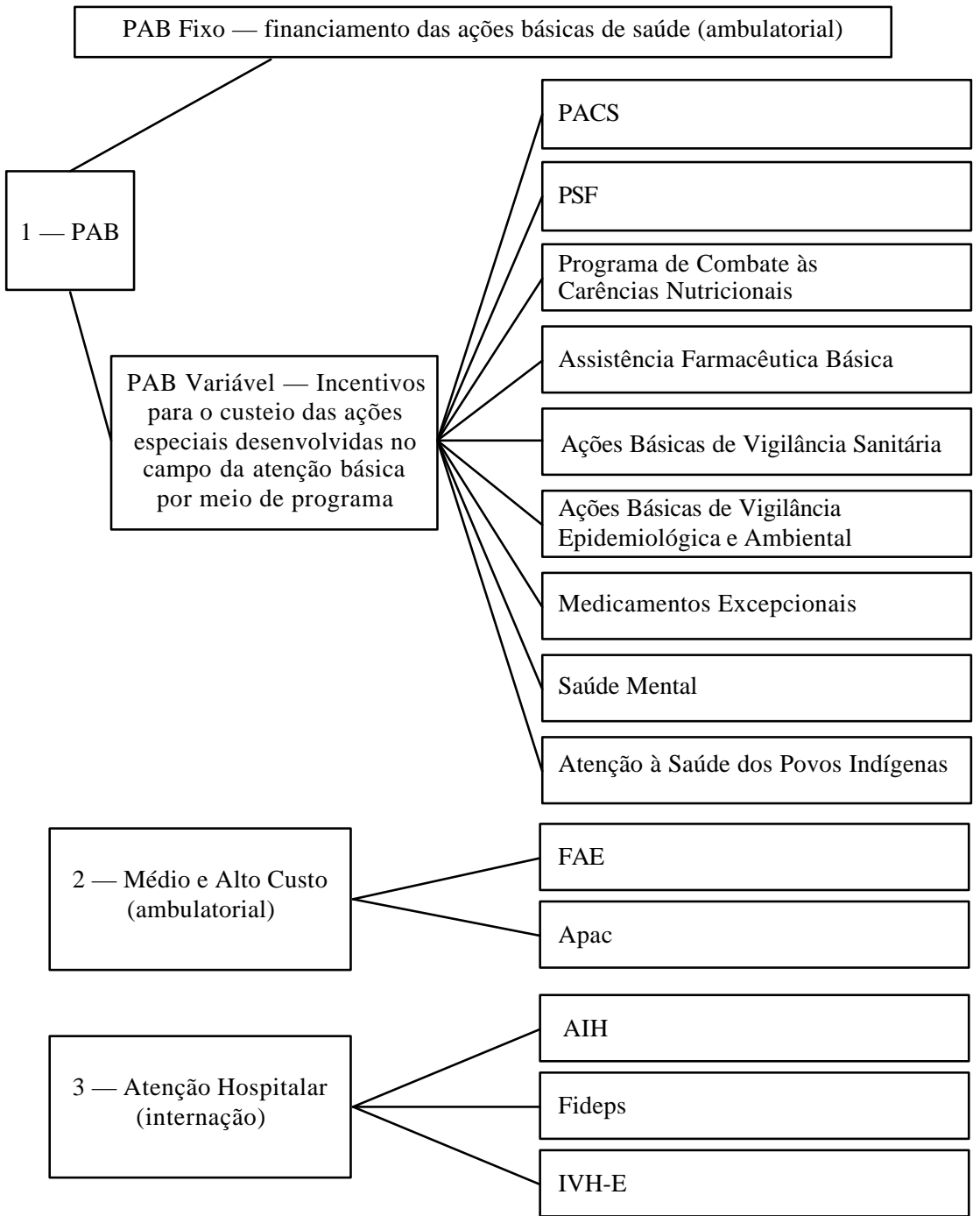




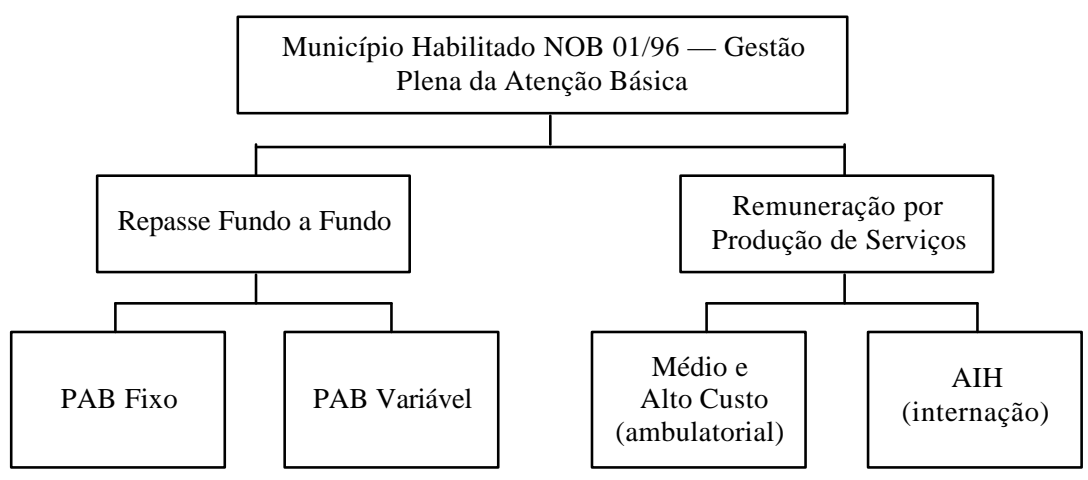

Já os municípios sob a Gestão Plena do Sistema Municipal passaram a ter responsabilidade imediata por todas as ações prestadas no município, sendo que todas as unidades ambulatoriais especializadas e hospitalares, estabelecidas no território municipal, estariam subordinadas aos órgãos executivos municipais (Arretche e Marques, 2000: 17-18). Nessa forma de gestão, ocorre a transferência regular e automática de recursos federais para atenção básica em saúde, acrescida de outros procedimentos de maior complexidade.

A fim de desempenhar suas funções, a Secretaria Municipal de Saúde deveria contar com a transferência, regular e automática, dos TFAMs,${ }^{17}$ do PBVS, e dos recursos referentes às ações de epidemiologia e controle de doenças. Contaria, ainda, com uma remuneração por serviços de vigilância sanitária de média e alta complexidade e pela execução do Programa Desconcentrado de Ações de Vigilância Sanitária, se assumido pelo município. A Secretaria Municipal de Saúde estaria autorizada, ainda, a estabelecer as normas complementares relativas ao pagamento dos prestadores de serviços em seu território, o que inclui a alteração dos valores dos procedimentos médicos previstos na tabela do SUS (ver Figura 7).

\section{Figura 7}

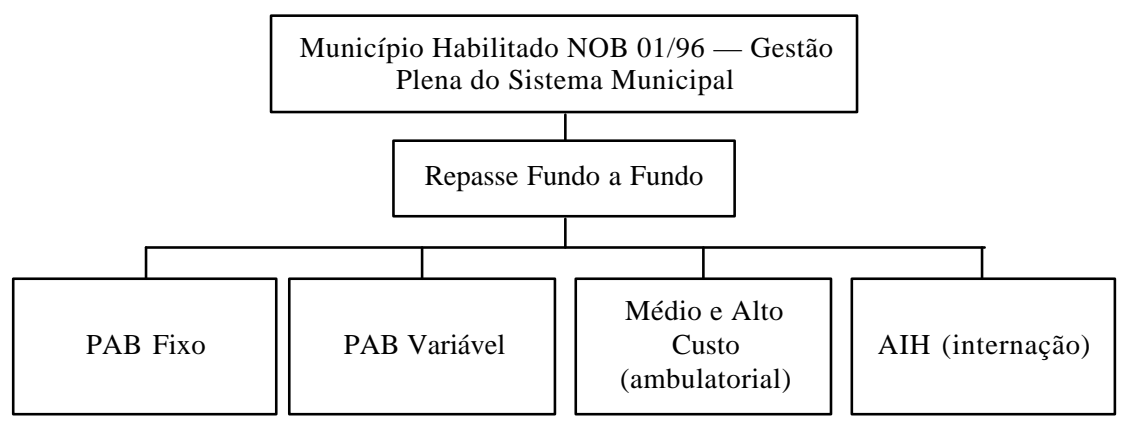


Para os Estados em Gestão Avançada do Sistema Estadual ${ }^{18}$ e Gestão Plena do Sistema Estadual ${ }^{19}$ foi definido o TFG do Estado, indicando a parcela a ser transferida de forma regular e automática fundo a fundo, ao Estado e aos municípios, incluindo os programas de assistência ambulatorial e hospitalar, vigilância sanitária e epidemiologia e controle de doenças.

Além disso, nos municípios não habilitados em nenhum tipo de gestão (atualmente representam um número muito pequeno), a transferência de recursos ocorre por comprovação de atendimento, mediante o faturamento de AIH e SIA, independentemente da origem dos gastos (públicos ou privados). Essas informações precisam ser repassadas regularmente ao Ministério da Saúde. Assim, os procedimentos da parte fixa do PAB, bem como as internações hospitalares e ambulatoriais, serão efetuadas por remuneração de serviços, a parte variável do PAB, por convênios (ver Figura 8).

\section{Figura 8}

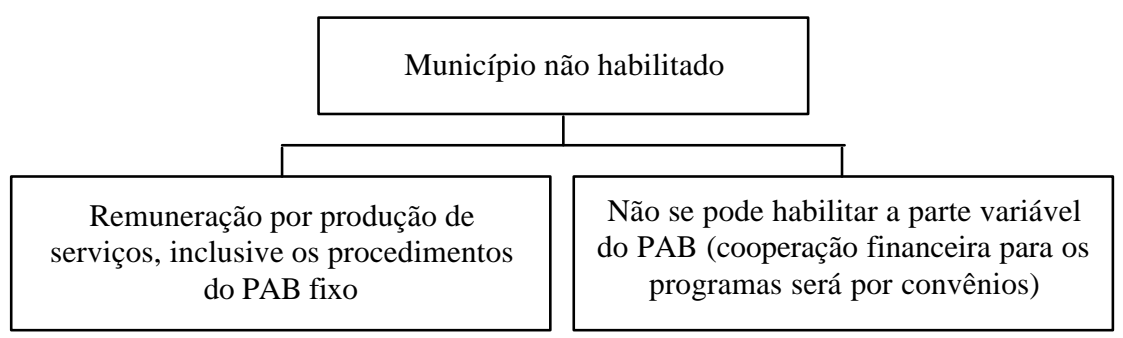

\section{Programas e ações implementadas pelo FNS e pela Funasa}

O FNS tem como finalidade prover recursos para a manutenção do Ministério da Saúde e para a cobertura das ações e serviços de saúde, a serem executados pelos municípios, Estados e Distrito Federal. De modo geral, alguns programas do FNS, que representam projetos específicos ou investimentos (obras, equipamentos e outros materiais permanentes, como é o caso do Reforço à Reorganização do Sistema Único de Saúde Reforsus), ${ }^{20}$ dependem da elaboração de um convênio, ou seja, um contrato que define as ações e as condições de repasse dos recursos, bem como a contrapartida.

Os principais programas implementados pelo FNS são: a) Qualidade e Eficiência do SUS; b) Qualidade do sangue; c) Prevenção, controle e assistência aos portadores de Doenças Sexualmente Transmissíveis/Aids; d) Prevenção e controle do câncer e assistência oncológica; e) Prevenção 
e controle das doenças crônico-degenerativas; f) Prevenção e controle da tuberculose e outras pneumopatias; g) Controle da hanseníase e de outras dermatoses; h) Gestão política de saúde; i) Saúde mental; j) Saúde da mulher; k) Saúde do trabalhador; 1) Saúde do jovem (Programa saúde do adolescente - PROSAD); m) Saúde da criança e aleitamento materno; n) Atenção à pessoa portadora de deficiência; o) Valorização e saúde do idoso/Programa de atenção integral à saúde do idoso; p) Profissionalização da enfermagem.

Por sua vez, a Funasa, criada em 16 de abril de 1991, tem como finalidade promover e executar ações e serviços de saúde pública. Nesse sentido, é responsável pela coordenação do Sistema Nacional de Vigilância Epidemiológica (SNVE). De acordo com a lei no 8.080/1990, a vigilância epidemiológica é "o conjunto de atividades que permite reunir a informação indispensável para conhecer, a qualquer momento, o comportamento ou história natural das doenças, bem como detectar ou prever alterações de seus fatores condicionantes, com o fim de recomendar oportunamente, sobre bases firmes, as medidas indicadas e eficientes que levem à prevenção e ao controle de determinadas doenças".

Assim, a Funasa colabora para a promoção e disseminação do uso da metodologia epidemiológica em todos os níveis do SUS, objetivando o estabelecimento de sistemas de informação e análises que permitam o monitoramento do quadro sanitário do país e subsidiem a formulação, implementação e avaliação das ações de prevenção e controle de doenças e agravos, a definição de prioridades e a organização dos serviços e ações de saúde.

Em todos os programas, a aplicação de recursos ocorre mediante a celebração de convênios ou um contrato com a Funasa, em que são definidas as ações e as condições de repasse dos recursos, bem como a contrapartida. As propostas que atendem aos critérios de elegibilidade estabelecidos para cada um dos projetos são passíveis de financiamento, de acordo com o limite orçamentário e a ordem das prioridades definidas. ${ }^{21}$

O percentual de contrapartida dos Estados, do Distrito Federal e dos municípios, quando devido, será calculado previamente pelo proponente do projeto, incidindo sobre o total dos recursos orçados no Plano de Trabalho, podendo ser proposta redefinição por parte do concedente, observados como limites mínimo e máximo os percentuais indicados no Quadro 1. Essa contrapartida poderá ser atendida por meio de recursos financeiros ou bens e serviços economicamente mensuráveis e será estabelecida de modo compatível com a capacidade financeira da respectiva unidade beneficiada.

A exigência de contrapartida acima estipulada não se aplica:

a) aos municípios que se encontrem em situação de calamidade pública formalmente reconhecida, durante o período que esta subsistir; 
b) aos municípios com até 25.000 habitantes, incluídos nos bolsões de pobreza identificados como áreas prioritárias no Programa Comunidade Solidária;

c) órgãos e entidades federais;

d) entidades de direito privado sem fins lucrativos; e

e) ONG's.

\section{Quadro 1: Contrapartida dos Estados, do Distrito Federal e dos municípios aos projetos da Funasa}

\begin{tabular}{l|c|c|c|c}
\hline \multirow{2}{*}{ Situação } & \multicolumn{2}{|c|}{ Municípios } & \multicolumn{2}{c}{$\begin{array}{c}\text { Estados } \\
\text { Distrito Federal }\end{array}$} \\
\hline & Mínimo & Máximo & Mínimo & Máximo \\
\cline { 2 - 5 } & $5 \%$ & $10 \%$ & -- & - \\
Até 25.000 habitantes & & & & \\
Das áreas da Sudam, Sudene e & $10 \%$ & $20 \%$ & $10 \%$ & $20 \%$ \\
Região Centro-Oeste & $10 \%$ & $40 \%$ & -- & - \\
Solicitantes no âmbito do SUS (*) & $20 \%$ & $40 \%$ & $20 \%$ & $40 \%$ \\
Os demais & &
\end{tabular}

Nota: (*) Exceto para municípios enquadráveis nos tópicos anteriores.

Os principais programas implementados pela Funasa são: a) Melhoria habitacional para o controle da doença de chagas; b) Sistemas de resíduos sólidos/Saneamento básico/Implantação e ampliação ou melhorias de sistemas de coleta, tratamento e destinação final de resíduos sólidos para controle de agravos; c) Serviços de drenagem para o controle da malária/ Saneamento básico/Drenagem e manejo ambiental em áreas endêmicas de malária; d) Melhorias sanitárias domiciliares/Saneamento Básico/ Implantação de melhorias sanitárias domiciliares para o controle de agravos; e) Sistemas de abastecimento de água/Saneamento Básico/Construção e ampliação ou melhoria dos sistemas de abastecimento de água para controle de agravos; f) Sistemas de esgotamento sanitário/Saneamento básico/ Construção e ampliação ou melhoria de sistema de coleta e tratamento de esgoto sanitário para controle de agravos; g) Atendimento integral à saúde dos povos indígenas/Etnodesenvolvimento das sociedades indígenas/ Funcionamento de unidades de saúde para atendimento às populações indígenas; h) Unidades de controle de zoonoses e de fatores biológicos de risco; i) Rede de frio para conservação de imunobiológicos; j) Estudos e pesquisas; k) Sistema Nacional de Vigilância em Saúde (Vigisus).

Em suma, os programas do Ministério da Saúde, mediante o FNS, a Funasa, a Fundação Oswaldo Cruz (Fiocruz) e a Agência Nacional de Vigilância Sanitária (Anvisa) podem ser agrupados em quatro grandes 
eixos, quais sejam, atendimento ambulatorial e hospitalar, que inclui os chamados PABs; prevenção; grupos populacionais; e aperfeiçoamento institucional do sistema. Os programas desses grandes eixos, que constam no Orçamento Geral da União e apresentam transferências para Estados e municípios, estão arrolados no Quadro 2.

A Tabela 1 explicita os gastos totais do Ministério da Saúde em seus principais programas. Em valores nominais, os gastos em ações de saúde pularam de R \$ 10 bilhões para R \$ 15,8 bilhões, entre 1996 e 1999. A "Assistência Hospitalar e Ambulatorial", incluindo os recursos do PAB fixo, do PSF e do PACS, absorveu o maior volume de recursos, R\$ 7,9 bilhões em 1996 e R 11 bilhões em 1999. Em segundo lugar, ficou a compra de medicamentos, incluindo medicamentos para combate do vírus HIV/Aids e o Programa Farmácia Básica.

Tabela 1: Despesas efetuadas pelo Ministério da Saúde (1996-1999)

Em valores nominais/R \$ milhões

\begin{tabular}{|c|c|c|c|c|c|}
\hline Despesa & Unidade & 1996 & 1997 & 1998 & 1999 \\
\hline 1. Ações finalísticas & & $10.042,7$ & $13.017,3$ & $12.995,4$ & $15.848,7$ \\
\hline $\begin{array}{l}\text { Assistência hospitalar e } \\
\text { ambulatorial (a) }\end{array}$ & FNS & $7.960,9$ & $9.755,1$ & $9.562,0$ & $11.077,5$ \\
\hline Medicamentos (b) & CEME/FNS & 230,8 & 569,7 & 569,7 & 960,3 \\
\hline Erradicação Aedes Aegypti & FNS/Funasa & 0,0 & 248,5 & 200,9 & 303,8 \\
\hline Saneamento básico & Funasa & 33,8 & 90,7 & 142,6 & 200,8 \\
\hline Controle de endemias & Funasa & 89,1 & 156,5 & 166,0 & 239,6 \\
\hline $\begin{array}{l}\text { Combate às carências } \\
\text { nutricionais }\end{array}$ & INAN/FNS & 31,6 & 101,7 & 59,0 & 139,8 \\
\hline $\begin{array}{l}\text { Aquisição de vacinas } \\
\text { e vacinação }\end{array}$ & Funasa & 118,5 & 163,1 & 172,8 & 263,1 \\
\hline Reforsus (c) & FNS & 0,0 & 34,9 & 159,2 & 229,2 \\
\hline Reaparelhamento das & & & & & \\
\hline Unidades do SUS & FNS & 14,7 & 52,0 & 132,9 & 174,6 \\
\hline Vigilância sanitária & FNS & 4,7 & 20,7 & 50,2 & 59,9 \\
\hline $\begin{array}{l}\text { Controle do câncer } \\
\text { cérvico-uterino }\end{array}$ & FNS & 0,0 & 28,5 & 37,6 & 46,5 \\
\hline Sangue e hemoderivados & FNS & 0,0 & 0,7 & 15,8 & 34,7 \\
\hline $\operatorname{AIDS}(\mathrm{d})$ & FNS & 74,7 & 67,9 & 52,2 & 106,5 \\
\hline Projeto Nordeste & FNS & 52,3 & 23,6 & 0,9 & 0,0 \\
\hline Produção de vacinas (e) & Fiocruz & 22,2 & 23,8 & 25,2 & 20,7 \\
\hline Hospitais próprios & FNS & 732,7 & 797,3 & 735,5 & 759,4 \\
\hline Anvisa & FNS & 0,0 & 0,0 & 0,0 & 72,5 \\
\hline Demais ações & Vários & 676,7 & 882,6 & 912,9 & $1.159,8$ \\
\hline 2. Pessoal & & $3.834,1$ & $3.996,4$ & $3.994,3$ & $4.330,3$ \\
\hline 3. Dívida & & 499,9 & $1.790,8$ & $2.333,9$ & 155,2 \\
\hline Total & & $14.376,7$ & $18.804,5$ & $19.323,6$ & $20.334,2$ \\
\hline
\end{tabular}

Fonte: CGOF/SPO/SE/MS.

Notas: (a) Inclui PAB, PACS e PSF; (b) Inclui AIDS e Farmácia Básica; (c) Recursos externos; (d) Exceto medicamentos; (e) Inclui os custos operacionais.

Observação: FNS; Central de Medicamentos/até 1997 (Ceme); Funasa; Fiocruz; Instituto Nacional de Alimentação e Nutrição/até 1997 (Inan). 
Quadro 2: Programas e unidades orçamentárias do Ministério da Saúde

\begin{tabular}{|c|c|c|c|c|c|}
\hline \multicolumn{2}{|c|}{ Programa/Unidade Orçamentária } & Fiocruz & Funasa & Anvisa & FNS \\
\hline \multicolumn{6}{|c|}{ Atendimento ambulatorial, hospitalar e pisos de atenção básica } \\
\hline 0023 & Atendimento Ambulatorial, Emergencial e Hospitalar & & \multirow[b]{6}{*}{$\mathrm{X}$} & \multirow{6}{*}{$\mathrm{X}$} & $\mathrm{X}$ \\
\hline 0001 & Saúde da Família & & & & $\mathrm{X}$ \\
\hline 0005 & Assistência Farmacêutica & $\mathrm{X}$ & & & $\mathrm{X}$ \\
\hline 0008 & Alimentação Saudável & & & & $\mathrm{X}$ \\
\hline 0010 & Vigilância Sanitária de Produtos e Serviços & & & & $\mathrm{X}$ \\
\hline 0013 & Vigilância Epidemiológica e Ambiental em Saúde & & & & \\
\hline \multicolumn{6}{|c|}{ Prevenção } \\
\hline 0007 & Qualidade do Sangue & \multirow{14}{*}{$\mathrm{X}$} & \multirow{7}{*}{$\mathrm{X}$} & \multirow{14}{*}{$\begin{array}{l}X \\
X\end{array}$} & $\mathrm{X}$ \\
\hline 0002 & $\begin{array}{l}\text { Prevenção e Controle de Doenças Transmissíveis } \\
\text { por Vetores }\end{array}$ & & & & $\mathrm{X}$ \\
\hline 0003 & $\begin{array}{l}\text { Prevenção, Controle e Assistência aos Portadores } \\
\text { de Doenças Sexualmente Transmissíveis e da Aids }\end{array}$ & & & & $\mathrm{X}$ \\
\hline 0019 & $\begin{array}{l}\text { Prevenção e Controle da Tuberculose e } \\
\text { outras Pneumopatias }\end{array}$ & & & & $\mathrm{X}$ \\
\hline 0011 & $\begin{array}{l}\text { Prevenção e Controle do Câncer e Assistência } \\
\text { Oncológica }\end{array}$ & & & & $\mathrm{X}$ \\
\hline 0020 & Controle da Hanseníase e de Outras Dermatoses & & & & $\mathrm{X}$ \\
\hline 0017 & $\begin{array}{l}\text { Prevenção e Controle das Doenças Crônico- } \\
\text { degenerativas (Hipertensão, Diabete, Cardiovascular, } \\
\text { Saúde Ocular e Prevenção da Cegueira) }\end{array}$ & & & & $\mathrm{X}$ \\
\hline 0014 & Prevenção e Controle da Malária & & $\mathrm{X}$ & & $\mathrm{X}$ \\
\hline 0015 & Prevenção e Controle da Dengue & & $\mathrm{X}$ & & $\mathrm{X}$ \\
\hline 0006 & $\begin{array}{l}\text { Prevenção e Controle das Doenças } \\
\text { Imunopreveníveis (vacinação) }\end{array}$ & & $\mathrm{X}$ & & \\
\hline 0024 & $\begin{array}{l}\text { Vigilância Sanitária de Portos, Aeroportos } \\
\text { e Fronteiras }\end{array}$ & & \multirow{4}{*}{$\begin{array}{l}X \\
X\end{array}$} & & \\
\hline 0028 & Prevenção e Controle das Infecções Hospitalares & & & & \\
\hline 0119 & Saneamento Básico & & & & $\mathrm{X}$ \\
\hline 0495 & Proágua - Gestão (a) & & & & \\
\hline \multicolumn{6}{|c|}{ Grupos populacionais - ações coletivas } \\
\hline 0018 & Saúde Mental & & \multirow{8}{*}{$\begin{array}{l}X \\
X\end{array}$} & & $\mathrm{X}$ \\
\hline 0021 & Saúde da Mulher & & & & $\mathrm{X}$ \\
\hline 0022 & Saúde do Trabalhador & & & & $\mathrm{X}$ \\
\hline 0027 & Saúde da Criança e Aleitamento Materno & & & & $\mathrm{X}$ \\
\hline 0066 & Valorização e Saúde do Idoso & & & & $\mathrm{X}$ \\
\hline 0026 & Saúde do Jovem (Saúde do Adolescente) & & & & $\mathrm{X}$ \\
\hline 0065 & Atenção à Pessoa Portadora de Deficiência (a) & & & & $\mathrm{X}$ \\
\hline$\underline{0150}$ & Etnodesenvolvimento das Sociedades Indígenas (a) & & & & \\
\hline \multicolumn{6}{|c|}{ Aperfeiçoamento institucional do sistema } \\
\hline 0004 & Qualidade e Eficiência do SUS & \multirow{6}{*}{$\begin{array}{l}X \\
X\end{array}$} & \multirow[t]{6}{*}{$\mathrm{X}$} & & $\mathrm{X}$ \\
\hline 0016 & Gestão da Política de Saúde & & & & $\mathrm{X}$ \\
\hline 0009 & Profissionalização da Enfermagem & & & & $\mathrm{X}$ \\
\hline 0012 & Pesquisa e Desenvolvimento em Saúde & & & & \\
\hline 0466 & Biotecnologia de Recursos Genéticos - Genoma (a) & & & & $\mathrm{X}$ \\
\hline 0025 & Saúde Suplementar (Planos de Saúde) & & & & $\mathrm{X}$ \\
\hline
\end{tabular}

Fonte: Estruturação do Plano Plurianual (2000/2003): visão do planejamento setorial da saúde. Brasília, DF: Ministério da Saúde/Secretaria Executiva, 2000.

Nota: (a) Programas interministeriais, gerenciados por outros ministérios. 


\section{Órgãos que intervêm nas transferências orçamentárias de projetos e atividades}

A partir da NOB 01/1993 ficaram definidos os mecanismos de gestão pluri-institucional, com a criação das comissões bipartites e tripartites de gestores, que consolidou o cenário da negociação entre os diferentes níveis de governo, sendo que o município ficou explicitamente instituído como gestor específico dos serviços de saúde.

Como vimos, o TFGE do Estado - constituído pela soma dos TFAs, da TFVS, e da TFECD - é definido com base na PPI e submetido pela Secretaria Estadual de Saúde ao Ministério de Saúde, após negociação na CIB e aprovação pelo Conselho Estadual de Saúde. O valor final do teto e suas revisões são fixados com base nas negociações realizadas no âmbito da CIT, observadas as reais disponibilidades financeiras do Ministério da Saúde e formalizadas em ato do ministério.

O TFGM do município, também definido pela PPI, é submetido pela Secretaria Municipal de Saúde à Secretaria Estadual de Saúde, após aprovação pelo Conselho Municipal de Saúde. O valor final desse teto e suas revisões são fixados com base nas negociações realizadas no âmbito da CIB, observados os limites do TFGE e formalizado em ato próprio do Secretário Estadual de Saúde.

Dessa forma, todos os valores referentes a pisos, tetos, frações, índices, bem como suas revisões, são definidos com base na PPI, negociados nas Comissões Intergestoras (CIB e CIT), formalizados em atos dos gestores estadual e federal e aprovados previamente nos respectivos Conselhos (Conselho Estadual de Saúde e CNS). São, portanto, instâncias de negociação e integração do SUS, a fim de proceder a harmonização dos gestores do sistema, a pactuação e programação das atividades de saúde, e a definição dos tetos financeiros dos sistemas municipais e estaduais (ver Figura 9).

Como se pode apreender, a elaboração da PPI deve se dar em um processo ascendente, de base municipal, configurando, também, as responsabilidades do Estado na busca crescente da eqüidade, da qualidade da atenção e na conformação da rede regionalizada e hierarquizada de serviços. $^{22}$ Os órgãos federais, estaduais e municipais, bem como os prestadores conveniados e contratados têm suas ações expressas na programação do município em que estão localizados, à medida em que estão subordinados ao gestor municipal.

A União define normas, critérios, instrumentos e prazos, aprova a programação de ações sob seu controle — inscritas na programação pelo Estado e seus municípios — incorpora as ações sob sua responsabilidade 
direta e aloca os recursos disponíveis, segundo os valores apurados na programação e negociados na CIT, cujo resultado é deliberado pelo CNS.

\section{Figura 9}

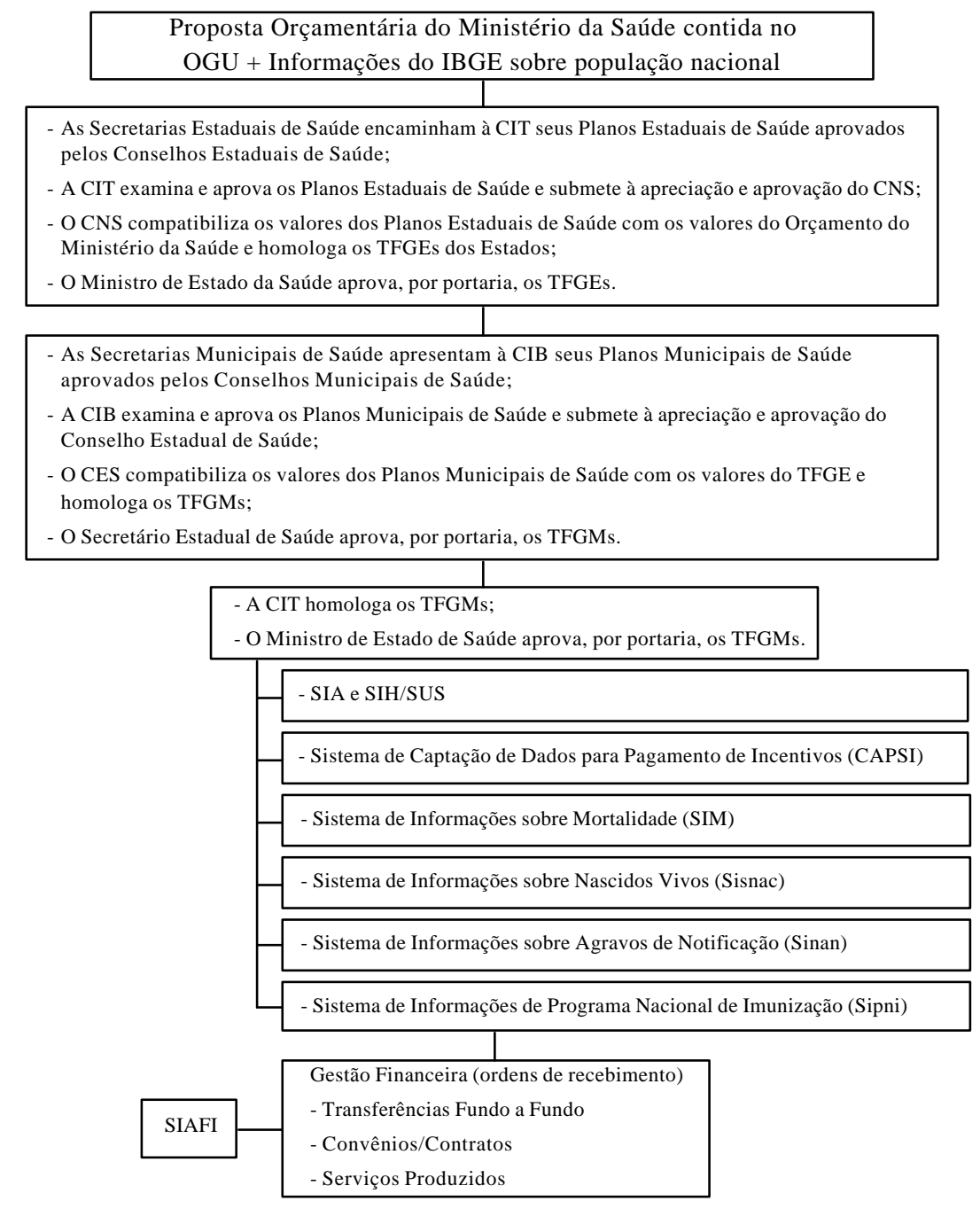

Em contrapartida, Estados e municípios devem alimentar um banco de dados do Ministério da Saúde: SIA/SUS; SIH/SUS; SIM; Sisnac; Sinan; Sipni.

Em suma, a elaboração da programação observa critérios e parâmetros definidos pelas Comissões Intergestoras e aprovados pelos respectivos Conselhos. No tocante aos recursos de origem federal, os critérios, prazos e fluxos de elaboração da programação integrada e de suas reprogramações periódicas ou extraordinárias, são fixados em ato 
normativo do Ministério da Saúde e traduzem as negociações efetuadas na CIT e as deliberações do CNS.

\section{Fontes de recursos}

Como previsto no art. 194 da Constituição, a saúde integra a Seguridade Social, juntamente com a Previdência e a Assistência Social. $\mathrm{O}$ art. 195 estabelece que a Seguridade Social será financiada com recursos provenientes dos orçamentos da União, dos Estados, do Distrito Federal e dos municípios, e de Contribuições Sociais.

A despeito de Estados e municípios participarem do financiamento do SUS, há uma relativa ausência de critérios e parâmetros para definir a participação dos governos subnacionais, fazendo com que todas as pressões para aumento dos recursos setoriais recaíam sobre a União. ${ }^{23}$ Observase, na Tabela 2, que na segunda metade da década, os gastos federais em saúde atingiram um patamar em torno de $\mathrm{R} \$ 18$ bilhões em termos reais, equivalendo a $2 \%$ do Produto Interno Bruto (PIB).

As principais fontes específicas da Seguridade Social incidem sobre a Folha de Salário (Fonte 154), o Faturamento (Fonte 153 - Cofins) e o Lucro Líquido (Fonte 151 - Lucro Líquido). Até 1992, todas essas fontes integravam o orçamento do Ministério da Saúde e ainda havia aporte significativo de fontes fiscais (Fonte 100 - Recursos Ordinários, provenientes principalmente da receita de impostos e taxas). A partir de 1993, deixou de ser repassada ao Ministério da Saúde a parcela da Contribuição sobre a Folha de Salário (Fonte 154, arrecadada pelo Instituto Nacional de Seguridade Social — INSS).

Tabela 2: Ministério da Saúde - gasto total, per capita e em proporção do PIB (1993-1999)

\begin{tabular}{|c|c|c|c|c|c|}
\hline & $\begin{array}{l}\text { R\$ milhões } \\
\text { corrente }\end{array}$ & $\begin{array}{c}\text { R\$ milhões } \\
\text { constante } \\
\text { Dezembro/1998 } \\
\text { (a) }\end{array}$ & Índices & $\begin{array}{c}\text { Per capita } \mathrm{R} \$ \text { de } \\
\text { Dez } / 1998\end{array}$ & $\begin{array}{c}\% \text { do } \\
\text { PIB }\end{array}$ \\
\hline 1993 & 297 & 12.822 & 100 & 85,0 & 2,11 \\
\hline 1994 & 7.498 & 13.021 & 102 & 85,2 & 2,15 \\
\hline 1995 & 14.937 & 18.614 & 145 & 120,1 & 2,31 \\
\hline 1996 & 14.376 & 16.154 & 126 & 102,8 & 1,85 \\
\hline 1997 & 18.569 & 19.394 & 151 & 121,8 & 2,14 \\
\hline 1998 (b) & 17.541 & 17.665 & 138 & 109,5 & 1,94 \\
\hline 1999 & 20.334 & 18.373 & 143 & 113,8 & 2,06 \\
\hline
\end{tabular}

Fonte: Siafi/Sidor, apud Piola e Biasoto Jr., 2001, p. 221.

Notas: (a) Valores deflacionados mês a mês pelo IGP/DI da Fundação Getulio Vargas (FGV);

(b) Não inclui R $\$ 1,78$ bilhão correspondente à dívida do Ministério da Saúde amortizada diretamente pela Secretaria do Tesouro Nacional. 
Atualmente, a quase totalidade dos recursos destinados ao Ministério da Saúde se origina de Contribuições Sociais, sobretudo da Contribuição para o Financiamento da Seguridade Social (Cofins) e da Contribuição sobre o Lucro Líquido de Empresas (CSLL), (ver Tabela 3). A partir de 1997, agregou-se a Contribuição Provisória sobre Movimentação Financeira (CPMF). Apesar de ter sido criada como fonte adicional de recursos, a CPMF não proporcionou o incremento esperado nos recursos setoriais, uma vez que houve redução da participação das outras fontes que tradicionalmente compunham o financiamento da saúde. ${ }^{24}$ A participação relativamente elevada dos Títulos do Tesouro e Operações de Crédito, em 1995 e 1996, deve-se aos empréstimos contraídos junto ao Fundo de Amparo ao Trabalhador (FAT). Os aportes provenientes de Fontes Fiscais são destinados praticamente à cobertura de despesas, tais como pessoal e encargos.

Tabela 3: Ministério da Saúde - distribuição das fontes de financiamento (1993-1999)

\begin{tabular}{l|r|r|r|r|r|r|r}
\hline & 1993 & 1994 & 1995 & 1996 & 1997 & 1998 & 1999 \\
\hline Recursos Ordinários do & 8,9 & 1,0 & 3,1 & 0,2 & 1,0 & 10,8 & 15,1 \\
Tesouro (Fonte 100) & & & & & & & \\
Títulos de Resp. do Tesouro Na- \\
cional (Fonte 144-149) & 15,1 & 1,6 & 2,6 & 3,3 & 2,8 & 0,5 & 0,1 \\
Operações de Crédito - & 2,6 & 0,0 & 7,6 & 8,2 & 0,0 & 0,0 & 0,1 \\
Internas (Fonte 144-149) & & & & & & & \\
Operações de Crédito - & 0,5 & 1,2 & 1,1 & 0,9 & 0,5 & 1,1 & 0,2 \\
Externas & 1,0 & 2,1 & 2,4 & 2,5 & 2,4 & 2,6 & 0,1 \\
Recursos Diretamente & 67,4 & 54,5 & 69,2 & 63,3 & 73,0 & 71,0 & 61,5 \\
Arrecadados (Fonte 150) & 10,7 & 12,9 & 20,2 & 20,8 & 19,3 & 8,0 & 13,2 \\
Contribuições Sociais & 25,1 & 34,0 & 49,1 & 42,5 & 25,9 & 26,0 & 26,3 \\
. CSLL da PJ (Fonte 151) & & & & & & & \\
. Cofins (Fonte 153) & 31,6 & 0,0 & 0,0 & 0,0 & 0,0 & 0,0 & 0,0 \\
. Contrib Empr. Trab. p/ & 0,0 & 0,0 & 0,0 & 0,0 & 27,8 & 37,0 & 22,0 \\
$\quad$ Seguridade Social (Fonte 154) \\
CPMF
\end{tabular}

Fonte: Siafi/Sidor, apud Piola e Biasoto Jr., 2001, p. 224. 
As transferências, regulares ou eventuais, da União, para Estados, municípios e Distrito Federal, estão condicionadas à contrapartida destes níveis de governo, em conformidade com as normas legais vigentes (Lei de Diretrizes Orçamentárias e outras). Assim, nas esferas estadual e municipal, além dos recursos oriundos dos respectivos Tesouros, o financiamento do SUS conta com recursos transferidos pela União aos Estados e pela União e Estados aos municípios. Esses recursos devem ser previstos no orçamento e identificados nos fundos de saúde estadual e municipal como receita operacional proveniente da esfera federal e/ou estadual e utilizados na execução de ações previstas nos respectivos planos de saúde e na PPI.

\section{Critérios de distribuição de recursos}

A lei no 8.080/1990, no art. 35, estabeleceu um conjunto de critérios para a definição de valores a serem transferidos aos Estados, Distrito Federal e municípios, "segundo análise técnica de programas e projetos", a saber:

a) perfil demográfico da região;

b) perfil epidemiológico da população a ser coberta;

c) características quantitativas e qualitativas da rede de saúde na área;

d) desempenho técnico, econômico e financeiro no período anterior;

e) níveis de participação do setor saúde nos orçamentos estaduais e municipais;

f) previsão do plano qüinquienal de investimento da rede; e

g) ressarcimento do atendimento a serviços prestados para outras esferas de governo.

O mesmo artigo determinou que "metade dos recursos destinados a Estados e municípios será distribuída segundo o quociente de sua divisão pelo número de habitantes, independentemente de qualquer procedimento prévio".

A lei no 8.142, no art. 3, definiu que os recursos para cobertura das ações e serviços de saúde a serem implementados pelos municípios, Estados e Distrito Federal "serão repassados de forma regular e automática", de acordo com os critérios previstos no art. 35 da lei no 8.080/1990, enunciados acima.

O decreto no 1.232 , de 30 de agosto de 1994, condicionou a transferência de recursos à existência de fundo de saúde e à apresentação de plano de saúde aprovado pelo respectivo conselho, do qual conste a contrapartida de recursos no orçamento do Estado, do Distrito Federal ou do município, dispensando a necessidade de convênio ou instrumento congênere. Determinou também que, até que o Ministério da Saúde - 
para o que tem o prazo de 180 dias — defina diretrizes a serem observadas na elaboração dos planos de saúde - com base nas características epidemiológicas e de organização dos serviços assistenciais, a distribuição de recursos fosse feita "exclusivamente segundo o quociente de sua divisão pelo número de habitantes, segundo estimativas populacionais fornecidas pelo IBGE".

Porém, estudos técnicos realizados no âmbito da CIT demonstraram que:

a) considerando a situação dos bancos de dados epidemiológicos - alguns em implantação, como o Sinasc, e o Sinan; e outros com informações consolidadas até 1990, como o SIM; considerando as informações inconsistentes sobre a capacidade instalada da rede de serviços de saúde (os cadastros de unidades de saúde existentes no SIA, e no SIH do SUS estavam em processo de atualização, bem como os levantamentos sobre os estabelecimentos de saúde);

b) considerando a inexistência de registro, acompanhamento e avaliação sistemáticos sobre o desempenho técnico e financeiro de Estados e municípios; e

c) considerando, por fim, o fato de que os recursos passíveis de transferência correspondiam a recursos de custeio, a saída possível para definição dos tetos financeiros era a análise do gasto histórico com atividades ambulatoriais e hospitalares (Lucchese, 1996: 127 e Oliveira Jr., 2000: 150).

Assim, o critério utilizado consistiu no levantamento da média mensal do gasto realizado por Estado, no período janeiro-junho de 1994, com a identificação da participação percentual relativa de cada um na média mensal de gastos do conjunto dos Estados, correspondente ao total do país. Feito esse mapeamento, distribuíram-se os recursos disponíveis segundo essa participação histórica e consolidaram-se as distorções existentes.

Porém, a NOB 01/1996 instituiu as transferências relacionadas ao PAB pela multiplicação da população do município por um valor per capita nacional. ${ }^{25} \mathrm{O}$ PAB passou a ser transferido diretamente, de forma regular e automática, ao município habilitado. Quando o município não estava habilitado, o PAB era transferido diretamente ao respectivo Estado, que fica responsável pelas ações. Assim, a distribuição de recursos do PAB de forma per capita procurou alterar a lógica predominante no financiamento das internações hospitalares e assistência ambulatorial, baseada na capacidade de oferta instalada. Apreende-se, por exemplo, que o critério populacional destinou recursos do SUS para municípios sem oferta ou rede hospitalar estruturada, efetuando um verdadeiro esforço distributivo. 
Como enunciado anteriormente, o Orçamento da União apresenta seis projetos relacionados aos serviços de saúde que levam em conta o critério populacional e que são conhecidos pelo nome de PAB. Todos esses projetos estão no órgão FNS, no Ministério da Saúde, mas pertencem a programas diferentes. Apenas dois PABs fazem parte do mesmo programa, quais sejam, PAB parte fixa e PAB parte variável. Ambos compõem o PSF. Os seis projetos relacionados aos PABs e os respectivos critérios de distribuição são:

a) $\mathrm{PAB}$ - parte fixa, cujo nome do projeto no Orçamento da União é "Atendimento Assistencial Básico com o Piso de Atenção Básica $\mathrm{PAB}$, referente à parte fixa nos municípios em Gestão Plena da Atenção Básica". Faz parte do PSF e sua distribuição faz-se diretamente ao município contemplado e equivale a $\mathrm{R} \$ 10,00$ per capita por ano; ${ }^{26}$

b) PAB - parte variável, cujo nome do projeto no Orçamento da União é "Incentivo Financeiro a Municípios Habilitados à Parte Variável do Piso de Atenção Básica — PAB, para a Saúde da Família". Esse projeto visa a incentivar os municípios a atenderem integralmente suas populações na assistência básica: ${ }^{27}$

c) PAB - parte variável relativa à farmácia básica, cujo nome do projeto no Orçamento Geral da União é "Incentivo Financeiro a Municípios Habilitados à Parte Variável do Piso de Atenção Básica — PAB para a Assistência Farmacêutica Básica — Farmácia Básica". Esse projeto pertence ao Programa Assistência Farmacêutica e equivale a R \$ 1,00 por habitante/ano. Destina-se à aquisição de medicamentos de uso mais freqüente na atenção básica. É distribuído trimestralmente aos municípios com população menor que 21 mil habitantes (de acordo com os dados do IBGE/1996);

d) $\mathrm{PAB}$ - parte variável relativa às carências nutricionais, cujo nome do projeto no Orçamento Geral da União é "Incentivo Financeiro a Municípios Habilitados à Parte Variável do Piso de Atenção Básica PAB para Ações de Combate às Carências Nutricionais". Esse projeto pertence ao Programa Alimentação Saudável, trata da distribuição do leite integral e óleo de soja e equivale a cerca de $\mathrm{R} \$ 180,00$ por criança/ano com idade entre 6 e 23 meses. Visa a atender 926.083 habitantes (crianças) nas deficiências de ferro e vitamina $\mathrm{A} ;{ }^{28}$

e) $\mathrm{PAB}$ - parte variável relativa à vigilância sanitária, cujo nome do projeto no Orçamento Geral da União é "Incentivo Financeiro a Municípios Habilitados à Parte Variável do Piso de Atenção Básica - PAB para Ações de Vigilância Sanitária". Destina-se ao financiamento das ações básicas de fiscalização e controle sanitário em produtos, serviços e ambientes sujeitos à vigilância sanitária, bem como às atividades de educação em vigilância sanitária. Esse projeto pertence ao Programa Vigilância 
Sanitária de Projetos e Serviços, e equivale a R \$ 0,25 por habitante/ano.

Para efeito do cálculo do montante de recursos a ser repassado a cada município será considerada a população estimada para o ano de 1997 pelo IBGE; ${ }^{29} \mathrm{e}$

f) $\mathrm{PAB}$ - parte variável relativa às Ações de Vigilância Epidemiológica e Ambiental, cujo nome do projeto no Orçamento Geral da União é "Incentivo Financeiro a Municípios Habilitados à Parte Variável do Piso de Atenção Básica — PAB para Ações de Vigilância Epidemiológica e Ambiental". São repassados recursos necessários à execução de ações básicas de investigação e de diagnóstico epidemiológico e ambiental de risco, bem como ações de controle, eliminação e erradicação de agentes de agravos e danos à saúde individual e coletiva da população.

Em resumo, os itens II, IV, V e VI da lei no 8.080/1990, aparentemente, foram pouco ou nada utilizados. $\mathrm{O}$ critério populacional foi assumindo relevância, mas os valores históricos continuaram influenciando os cálculos dos tetos de recursos direcionados aos diferentes Estados da federação. Isso pode ser observado no Quadro 3, que explicita um exemplo hipotético representativo da composição do teto financeiro de um município, elaborado por uma equipe do Ministério da Saúde (Secretaria Executiva/Departamento de Controle, Avaliação e Auditoria/Coordenação Geral de Análise de Gestão/Coordenação de Controle das Ações). A maioria dos recursos, $77 \%$, ainda é alocada de acordo com o SIA e o SIH, portanto, associado à capacidade de oferta instalada (faturamento de serviços prestados). Os programas, que fogem desse critério, representam apenas $23 \%$ do total. ${ }^{30}$

De modo geral, as transferências no âmbito dos programas de atenção básica à saúde totalizam cerca de R \$ 2,2 bilhões/ano, representando 21,3\% do total dos recursos gastos pelo Ministério da Saúde (Serra e Afonso, 1999: 21 e Marques e Mendes, 2000: 3). Isso faz com que as regiões mais carentes do país, que não contam com uma infra-estrutura avançada em termos de rede de saúde, tenham ampliado sua participação na distribuição de recursos, mas ainda permanecem relativamente prejudicadas, explicitando o enorme conflito distributivo entre as unidades federativas.

De acordo com os dados divulgados pelo Datasus, a Região Sudeste absorveu 46,3\% dos gastos do Ministério da Saúde em 1999; a Região Nordeste, 26,2\%; a Região Sul, 15,7\%; a Região Centro-Oeste, 6,2\%; e a Região Norte, 5,6\%. Esses dados refletem a grande heterogeneidade regional do país e que condena os governos dos municípios mais pobres e com maiores carências a funcionarem com menos recursos.

Piola e Biasoto Jr. (2000) explicitaram que a distribuição regional do gasto público com saúde - um dado importante do ponto de vista da 
eqüidade na alocação dos gastos públicos — seria melhor evidenciada se computasse o dispêndio per capita em saúde total (das três esferas de governo) nas regiões brasileiras. Esse indicador mostra que o gasto público permanece muito desigual entre as diferentes regiões e Estados, mas as desigualdades se devem mais às diferenças nos aportes dos Estados e municípios. O dispêndio público total per capita variou entre $\mathrm{R} \$ 186,10$ na Região Sudeste e R \$ 93,50 na Nordeste, portanto, apresentando uma diferença de R \$ 82,60 (ver Tabela 4). Entretanto, a variação do aporte federal para essas regiões foi de apenas $\mathrm{R} \$ 20,10$.

\section{Quadro 3: Exemplo da composição de teto financeiro}

\begin{tabular}{l|r|r}
\hline & \multicolumn{1}{|c|}{$\mathbf{R} \$$} & \multicolumn{1}{|c}{$\%$} \\
\hline Teto Financeiro & 157.702 .566 & 100,00 \\
PAB Fixo & 28.825 .491 & 18,28 \\
PAB Variável & 7.449 .728 & 4,72 \\
PACS & 3.450 .000 & 2,19 \\
PSF & 420.000 & 0,26 \\
Ações Básicas de Vigilância Sanitária & 713.275 & 0,45 \\
Carências Nutricionais & 2.107 .376 & 1,33 \\
Assistência Farmacêutica Básica & 759.078 & 0,49 \\
Procedimentos de Alta e Média Complexidade + AIH & & \\
(SIA/SIH) & 121.427 .347 & 77,00 \\
\hline
\end{tabular}

Fonte: Mangueira et alii, 1999, p. 11.

Tabela 4: Distribuição do gasto público per capita, por região, segundo as instâncias de governo (1995)

Em R \$ 1,00 dezembro/1998

\begin{tabular}{l|c|c|c|c}
\hline & União & Estados & Municípios & Total \\
\hline Norte & 61,2 & 31,7 & 5,7 & 98,6 \\
Nordeste & 67,1 & 14,9 & 12,3 & 93,5 \\
Sudeste & 87,2 & 57,1 & 22,5 & 186,1 \\
Sul & 78,1 & 16,3 & 25,2 & 126,2 \\
Centro-Oeste & 123,8 & 26,6 & 8,6 & 164,5 \\
\hline Total & 96,1 & 35,0 & 17,2 & 158,3 \\
\hline
\end{tabular}

Fonte: Siafi/Sidor, apud Piola e Biasoto Jr., 2000, p. 16. 


\section{Descentralização dos gastos federais em saúde}

Entre 1996 e 1999, houve um aumento relativo nas transferências de recursos federais promovidas pela Funasa e FNS. Essas unidades orçamentárias respondiam por 5,47\% do total das transferências federais (voluntárias e obrigatórias) em 1996 e passaram para 14,78\% em 1999 (ver Tabelas 5 e 6). Além disso, pode-se observar uma clara tendência na municipalização dos gastos federais em saúde, como estabelecido nas estratégias do Ministério da Saúde. A participação dos municípios nas transferências relacionadas com a atenção à saúde dobrou no período analisado. Passou de 12,32\% do total das transferências federais em 1996, para $25,7 \%$ em 1999.

Tabela 5: Total das transferências

federais, pelas unidades orçamentárias do Ministério da Saúde (1996-1999)

\begin{tabular}{l|r|r|r|r|r|r|r|r|r|r|r|r}
\hline \multirow{2}{*}{$\begin{array}{l}\text { Unidade } \\
\text { orçamentária }\end{array}$} & \multicolumn{3}{|c|}{1996} & \multicolumn{3}{|c|}{1997} & \multicolumn{3}{|c|}{1998} & \multicolumn{3}{c}{1999} \\
\cline { 2 - 11 } & Estado & Mun. & Total & Estado & Mun. & Total & Estado & Mun. & Total & Estado & Mun. & Total \\
\hline Funasa & 33,9 & 54,9 & 88,9 & 131,7 & 136,0 & 267,8 & 149,3 & 201,9 & 351,2 & 158,7 & 347,8 & 506,6 \\
FNS & 84,8 & $1.477,9$ & $1.562,7$ & 174,8 & $2.258,9$ & $2.433,8$ & 421,2 & $4.011,3$ & $4.432,6$ & 728,0 & $5.760,6$ & $6.488,6$ \\
Subtotal & 118,7 & $1.532,8$ & $1.651,6$ & 306,5 & $2.394,9$ & $2.701,6$ & 570,5 & $4.213,3$ & $4.783,8$ & 886,7 & $6.108,4$ & $6.995,2$ \\
Transferências & & & & & & & & & & & & \\
voluntárias & $3.024,0$ & $2.923,6$ & $5.947,7$ & $3.895,9$ & $4.331,3$ & $8.227,2$ & $4.597,1$ & $6.730,8$ & $11.328,0$ & $3.934,6$ & $8.828,8$ & $12.763,4$ \\
$\begin{array}{l}\text { Transferências } \\
\text { obrigatórias }\end{array}$ & $14.688,6$ & $9.519,4$ & $24.208,0$ & $16.414,0$ & $10.865,7$ & $27.279,7$ & $19.023,7$ & $13.068,9$ & $32.092,7$ & $19.613,6$ & $14.939,7$ & $34.553,3$ \\
\hline Total & $17.712,7$ & $12.443,0$ & $30.155,7$ & $20.309,9$ & $15.197,0$ & $35.507,0$ & $23.620,9$ & $19.799,8$ & $43.420,7$ & $23.548,1$ & $23.768,6$ & $47.316,7$ \\
\hline
\end{tabular}

Tabela 6: Total das transferências federais, pelas unidades orçamentárias do Ministério da Saúde (1996-1999)

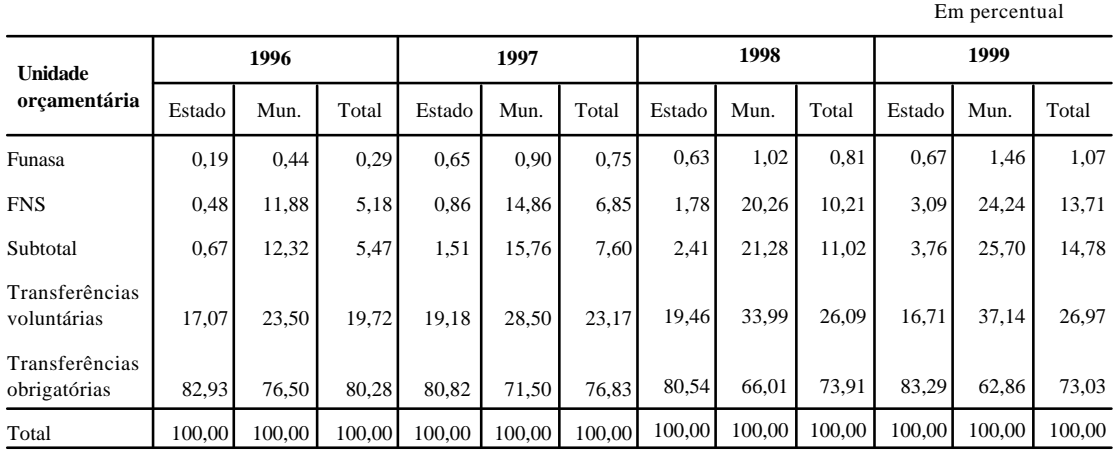

Fonte: Orçamento Geral da União, 2000, Brasília, DF. 
Essa tendência à municipalização dos gastos federais em saúde fica ainda mais evidente se se considera sua participação apenas no volume de transferências voluntárias. A Tabela 7 mostra que os municípios absorveram 50,55\% das transferências federais voluntárias em 1996 e saltaram para 65,25\% em 1999. Contudo, a Carta da XI Conferência Nacional de Saúde (Brasília, DF, 15-19 de dezembro de 2000) reconheceu: "consideramos que a verdadeira municipalização ainda não é uma realidade para todo o país, embora tenha ampliado significativamente o acesso da população a serviços de saúde com maior qualidade, diferenciando o modelo de atenção e qualificando a gestão descentralizada" (http://www.datasus.gov.br/cns/11Conferencia XICNS_CARTA_FINAL.htm).

\section{Tabela 7: Transferências voluntárias pelas Unidades Orçamentárias do Ministério da Saúde (1996-1999)}

\begin{tabular}{|c|c|c|c|c|c|c|c|c|c|c|c|c|}
\hline & & & & & & & & & & & percent & ual \\
\hline \multirow{2}{*}{$\begin{array}{l}\text { Unidade } \\
\text { orçamentária }\end{array}$} & \multicolumn{3}{|c|}{1996} & \multicolumn{3}{|c|}{1997} & \multicolumn{3}{|c|}{1998} & \multicolumn{3}{|c|}{1999} \\
\hline & Estado & Mun. & Total & Estado & Mun. & Total & Estado & Mun. & Total & Estado & Mun. & Total \\
\hline Funasa & 1,12 & 1,88 & 1,50 & 3,38 & 3,14 & 3,26 & 3,25 & 3,00 & 3,10 & 4,04 & 3,94 & 3,97 \\
\hline FNS & 2,80 & 50,55 & 26,27 & 4,49 & 52,15 & 29,58 & 9,16 & 59,60 & 39,13 & 18,50 & 65,25 & 50,84 \\
\hline Subtotal & 3,92 & 52,43 & 27,77 & 7,87 & 55,29 & 32,84 & 12,41 & 62,60 & 42,23 & 22,54 & 69,19 & 54,81 \\
\hline Total & 100,00 & 100,00 & 100,00 & 100,00 & 100,00 & 100,00 & 100,00 & 100,00 & 100,00 & 100,00 & 100,00 & 100,00 \\
\hline
\end{tabular}

Tabela 8: Orçamento Geral da União 2000 - autorizado para o Ministério da Saúde

\begin{tabular}{|c|c|c|c|c|c|c|c|c|}
\hline & & & & & & & & Em R\$ mil \\
\hline Código & $\begin{array}{l}\text { Unidade } \\
\text { Orçamen- } \\
\text { tária }\end{array}$ & 30 & 40 & 50 & 72 & 90 & 99 & Total \\
\hline 36201 & Fiocruz & 3.636 & 50 & 14.897 & 145 & 251.350 & 0 & 270.079 \\
\hline 36211 & Funasa & 128.548 & 353.054 & 80.707 & 118.710 & 1.825 .836 & 4.617 & 2.511 .474 \\
\hline 36212 & Anvisa & 11.579 & 0 & 12.386 & 13.200 & 121.152 & 0 & 158.318 \\
\hline 36901 & FNS & 1.278 .984 & 6.822 .813 & 334.801 & 82.846 & 8.746 .375 & 17.796 & 17.283 .616 \\
\hline & $\begin{array}{l}\text { Subtotal - } \\
\text { Min.da } \\
\text { Saúde }\end{array}$ & 1.422 .747 & 7.175 .917 & 442.791 & 214.901 & 10.944 .713 & 22.413 & 20.223 .487 \\
\hline & $\begin{array}{l}\text { OGU - } \\
\text { Total }\end{array}$ & 28.286 .307 & 27.334 .553 & 1.310 .088 & 451.585 & 948.405 .781 & 4.994 .058 & 1.013 .750 .924 \\
\hline
\end{tabular}

Fonte: Orçamento Geral da União, 2000, Brasília, DF.

Nota: Modalidades de Aplicação: 30 - Transferências aos Estados e ao DF; 40 — Transferências aos municípios; 50 - Transferências a Instituições Privadas sem Fins Lucrativos; 72 — Transferências ao Exterior - Organismos Internacionais; 90 - Aplicação Direta; 99 - Aplicação a Definir. 
O Orçamento Geral da União (2000) prevê, para o Ministério da Saúde, um volume total de gastos de R $\$ 20,2$ bilhões, sendo R $\$ 1,42$ bilhão transferido aos Estados e Distrito Federal, R $\$ 7,17$ bilhões transferidos aos municípios e R $\$ 10,90$ bilhões aplicados diretamente pela União (deve-se observar que aqui se encontram os gastos com pessoal, por exemplo) (ver Tabela 8). O TFG do Estado de São Paulo, que inclui os recursos direcionados aos municípios, é de $\mathrm{R} \$ 2,8$ bilhões, representando 14,1\% do total de gastos do Ministério da Saúde. A Tabela 9 distribui o TFG do Estado entre as ações executadas pelos municípios e pelo Estado.

A dotação orçamentária de julho de 2000 apresenta R \$ 227,4 milhões direcionados para o Estado de São Paulo (inclui o PAB dos municípios não habilitados) e $\mathrm{R}$ \$1.051,7 milhões destinados aos municípios paulistas, o que explicita mais uma vez a tendência à municipalização dos gastos em saúde. A soma dos valores alocados ao Estado e aos municípios totaliza $\mathrm{R} \$ 1.279$ milhões, representando $14,9 \%$ do total das transferências voluntárias federais em saúde.

Os programas de custeio dos serviços de saúde básica - "Atendimento Ambulatorial, Emergencial e Hospitalar em Regime de Gestão Plena do Sistema Único de Saúde - SUS" e "Saúde da Família (Atendimento Assistencial Básico com o Piso de Atenção Básica)" - concentram a maior proporção dos recursos federais transferidos para o Estado de São Paulo durante o ano 2000. Juntos, esses dois programas somaram $\mathrm{R} \$ 165,4$ milhões, representando $42,57 \%$ do total.

\section{Projetos e atividades federais executados pelo governo do Estado de São Paulo}

Atualmente, o Estado de São Paulo está habilitado em Gestão Avançada do Sistema Estadual. Os 645 municípios do Estado de São Paulo estão habilitados da seguinte forma: 478 em Gestão Plena de Atenção Básica, representando 74,1\% do total; 159 em Gestão Plena do Sistema Municipal, correspondendo a 24,6\% do total, e oito não estão habilitados, representando 1,3\% do total. Os argumentos que justificam a posição do Estado de São Paulo na NOB 01/96 em Gestão Avançada e não em Gestão Plena são controversos e de distintas naturezas, não necessariamente excludentes.

Do ponto de vista do governo do Estado de São Paulo, o TFG relativamente baixo diante da capacidade instalada no Estado seria o principal argumento que justificaria a decisão do Estado em permanecer em Gestão Avançada, pois no período recente houve a inauguração de oito novos hospitais (2.400 novos leitos) sem que houvesse alteração no teto. ${ }^{31}$ Assim, a situação de entrada dos Estados mais desenvolvidos, como São Paulo, 
dificulta a definição dos tetos, pois os valores históricos não dão conta dos custos das ações de alta e média complexidade dos novos complexos hospitalares e, portanto, os tetos tornam-se insuficientes. No entanto, os Estados que apresentam uma situação de entrada relativamente adequada, interessam-se por implementar a habilitação plena do sistema.

Do ponto de vista da União, a manutenção do teto representa uma forma de forçar o Estado de São Paulo a ampliar seus gastos no SUS. O jogo de forças políticas irá determinar o processo, mas apreende-se que a política de descentralização das ações de saúde aparentemente limita a própria descentralização, uma vez que fica restrita à distribuição dos recursos de origem federal.

O Estado de São Paulo não está habilitado na Gestão Plena em decorrência do fato de não atender o critério de ter $50 \%$ do Teto Financeiro repassado, fundo a fundo, aos municípios, uma vez que o município de São Paulo não está habilitado em nenhuma condição e os hospitais universitários continuam sob gestão estadual. ${ }^{32}$ Diante disso, Arretche e Marques (2000) defendem que o governo do Estado de São Paulo não implementou uma política ativa e continuada de municipalização das ações de saúde. Tendeu a concentrar poder e recursos em sua própria secretaria de saúde estadual. $^{33}$

De todo modo, estar habilitado em Gestão Avançada não significa receber menos recursos, mas sim receber de forma diferente. Caso o Estado fosse habilitado na Gestão Plena, além dos recursos dos municípios não habilitados, todos os recursos que hoje são pagos por produção de serviços aos municípios na condição básica seriam depositados no Fundo Estadual de Saúde, não mais por faturamento, mas em cima de uma série histórica; além disso, esse depósito passaria a ser antecipado. Isso daria ao Estado um poder de gestão muito maior. Portanto, parece não haver uma discordância em relação ao processo de descentralização; há, sim, em relação aos valores do teto financeiro, pagar via Fundo de Ações Estratégicas e de Compensações (FAEC), ${ }^{34}$ em vez de aumentar o teto etc. 
Tabela 9: Transferências de recursos

para o Estado de São Paulo (1999)

\begin{tabular}{|c|c|c|c|c|}
\hline & & & & $\mathrm{R} \$ \mathrm{mil}$ \\
\hline & & Municípios & Estado & Total \\
\hline $\begin{array}{l}\text { Internação } \\
\text { Hospitalar (MS) }\end{array}$ & $\begin{array}{l}\text { Faturamento de AIH pode ser para o ESP ou } \\
\text { para municípios }\end{array}$ & 866.711 & - & 866.711 \\
\hline $\begin{array}{l}\text { Atendimento } \\
\text { Ambulatorial (MS) }\end{array}$ & $\begin{array}{l}\text { Faturamento de SIA pode ser para o ESP ou } \\
\text { para municípios }\end{array}$ & 851.890 & - & 851.890 \\
\hline $\begin{array}{l}\text { Assistência } \\
\text { Hospitalar e } \\
\text { Ambulatorial }\end{array}$ & $\begin{array}{l}\text { - Transferências ao ESP referente a municípios } \\
\text { não habilitados em nenhuma condição de } \\
\text { gestão ou em gestão plena de atenção básica }\end{array}$ & & & \\
\hline (Gestão Plena) & $\begin{array}{l}\text { - Transferências aos municípios em gestão } \\
\text { plena do sistema municipal }\end{array}$ & 670.996 & - & 670.996 \\
\hline $\begin{array}{l}\text { Assistência Hospit./ } \\
\text { Ambulat. Dif. Mun. }\end{array}$ & Adicional & 6.927 & - & 6.927 \\
\hline $\begin{array}{l}\text { Compens. Alta } \\
\text { Complexidade (Mun.) }\end{array}$ & Extrateto (em 2000 chama FAEC) & 505 & - & 505 \\
\hline $\begin{array}{l}\text { Urgência/Emergência } \\
\text { (Mun.) }\end{array}$ & Extrateto (em 2000 chama FAEC) & 4.575 & - & 4.575 \\
\hline $\begin{array}{l}\text { Gestantes de } \\
\text { Alto Risco (Mun.) }\end{array}$ & Extrateto (em 2000 chama FAEC) & 1.334 & - & 1.334 \\
\hline Neurocirurgia (Mun.) & Extrateto (em 2000 chama FAEC) & 2.373 & - & 2.373 \\
\hline UTI (Mun.) & Extrateto (em 2000 chama FAEC) & 3.017 & - & 3.017 \\
\hline $\begin{array}{l}\text { Câncer de Colo } \\
\text { Uterino (Mun.) }\end{array}$ & Extrateto (em 2000 chama FAEC) & 2.158 & - & 2.158 \\
\hline Transplantes (Mun.) & Extrateto (em 2000 chama FAEC) & 699 & - & 699 \\
\hline $\begin{array}{l}\text { Cirurgia de Catarata } \\
\text { (Mun.) }\end{array}$ & Extrateto (em 2000 chama FAEC) & 4.632 & - & 4.632 \\
\hline $\begin{array}{l}\text { Cirurgia de Hérnia } \\
\text { Inguinal (Mun.) }\end{array}$ & Extrateto (em 2000 chama FAEC) & 291 & - & 291 \\
\hline $\begin{array}{l}\text { Medicamentos para } \\
\text { Transplantes Mun. }\end{array}$ & Extrateto (em 2000 chama FAEC) & 744 & - & 744 \\
\hline $\begin{array}{l}\text { Programa de } \\
\text { Tuberculose (Mun.) }\end{array}$ & Extrateto (em 2000 chama FAEC) & 155 & - & 155 \\
\hline Cirurgia de Mama (Mun.) & Extrateto (em 2000 chama FAEC) & 1 & - & 1 \\
\hline $\begin{array}{l}\text { Cirurgia da Próstata } \\
\text { (Mun.) }\end{array}$ & Extrateto (em 2000 chama FAEC) & 198 & - & 198 \\
\hline $\begin{array}{l}\text { Cirurgia de Varizes } \\
\text { (Mun.) }\end{array}$ & Extrateto (em 2000 chama FAEC) & 331 & - & 331 \\
\hline $\begin{array}{l}\text { Cirurgia deformidades } \\
\text { do Crânio-facial } \\
\text { (Municípios) }\end{array}$ & Extrateto (em 2000 chama FAEC) & 25 & & 25 \\
\hline PAB Fixo (Estado) & $\begin{array}{l}\text { Transferência para o ESP, referente aos muni- } \\
\text { cípios não habilitados em nenhuma condição } \\
\text { de gestão }\end{array}$ & & 79.241 & 79.241 \\
\hline PAB Fixo (Plena) & $\begin{array}{l}\text { Transferências aos municípios que estão em } \\
\text { Gestão Plena de Atenção Básica }\end{array}$ & 261.529 & - & 261.529 \\
\hline PACS (Mun.) & PAB - Variável & 4.945 & - & 4.954 \\
\hline PSF (Municípios) & PAB - Variável & 5.806 & - & 5.806 \\
\hline $\begin{array}{l}\text { Vigilância Sanitária } \\
\text { (Mun.) }\end{array}$ & PAB - Variável & 6.143 & - & 6.143 \\
\hline $\begin{array}{l}\text { Carência Nutricional } \\
\text { (Mun.) }\end{array}$ & PAB - Variável & 8.344 & - & 8.344 \\
\hline $\begin{array}{l}\text { Farmácia Básica } \\
\text { (Estado) }\end{array}$ & PAB - Variável & - & 29.581 & 29.581 \\
\hline $\begin{array}{l}\text { Medicamentos para } \\
\text { Saúde Mental (Estado) }\end{array}$ & PAB - Variável & - & 807 & 807 \\
\hline Total & & 2.704 .337 & 109.628 & 2.813 .965 \\
\hline
\end{tabular}

Fonte: Ministério da Saúde.

Nota: O FAEC, refere-se a procedimentos de alta complexidade, bem como à compensação interestadual, uma vez que São Paulo dispõe de uma das redes de serviços complexas e recebe pacientes de outros Estados do país. 


\section{Considerações finais}

Arretche e Rodriguez (1999: 129-130) sinalizaram duas críticas sobre o processo de descentralização da saúde. Em primeiro lugar, o processo na saúde se realiza sob forte normatização, tanto pelas instâncias centrais do Ministério da Saúde, quanto pelo CNS, órgão estruturante do SUS. Considerando que o sistema de repasses de recursos está centralizado no governo federal, por um lado a rigidez dos princípios do SUS, em termos normativos, pode facilitar o controle e reduzir as possibilidades de fraudes e malversação dos recursos. Por outro lado, o processo em curso assemelha-se a uma "descentralização tutelada", isto é, pode haver uma dose excessiva de controle sobre os meios de operação e fracos instrumentos de avaliação da cobertura e da qualidade dos serviços. A excessiva normatização pode representar um dos fatores responsáveis pela baixa capacidade de inovação das instâncias descentralizadas de governo. Esse resultado constitui, na prática, um efeito perverso e não esperado do modelo implementado, uma vez que, com a descentralização - e, assim, com a maior proximidade de gestores e beneficiários - a expectativa era que fossem facilitadas as inovações.

Em segundo lugar, a permanência do sistema de pagamento por produção limita a autonomia das instâncias descentralizadas, pela rigidez que impõe às possibilidades de adequação local da oferta de serviços, uma vez que o principal mecanismo de acesso aos recursos federais está vinculado à prestação de serviços de natureza curativa. A margem para inovação no plano local fica limitada pelo volume de recursos próprios disponíveis, já que os oriundos das transferências federais estão vinculados a um dado tipo de atuação.

No mesmo sentido, Elias (2000: 219) afirma que "a partilha de recursos financeiros se dá, na prática, sob o estrito controle da União em detrimento da eqüidade e da liberdade da esfera municipal para formular sua política de saúde e exercer o comando sobre a produção local de serviços de saúde. Nesses termos, o SUS configura-se como uma descentralização parcial e incompleta e protegida pela (e para a) União".

$\mathrm{O}$ teto financeiro de Estados e municípios, que conta com várias subdivisões (PAB fixo, PAB variável, média e alta complexidade ambulatorial, internação hospitalar, FAEC, subtetos para campanhas e outras atividades etc.), é fonte permanente de atrito entre as esferas de governo, tendo os Estados e os municípios defendido a plena autonomia na gestão dos tetos financeiros descentralizados. Isso porque, sem uma autonomia real, "Estados e municípios, mesmo recebendo os recursos federais fundo a fundo, continuariam a ser meros executores da política traçada pelo gestor federal" (Oliveira Jr, 2000: 152). Além disso, "a tutela federal sobre o uso dos recursos transferidos tenderia a aumentar com a 
criação das agências de regulação (vigilância sanitária, saúde suplementar), que dificultariam ainda mais a unificação do teto financeiro (atualmente, muito compartimentado), uma vez que cada uma deverá formular suas próprias regras para a transferência financeira e a conseqüente avaliação dos gestores estaduais e municipais" (Oliveira Jr., 2000: 151). ${ }^{35}$

Contudo, a autonomia de Estados e municípios na utilização dos recursos precisaria ser mais debatida. A crítica ao modelo de descentralização tutelada pela esfera federal e operada por meio do financiamento corre o risco de uma idealização da esfera municipal. Em princípio, não há nada de implicitamente virtuoso no nível local que não possa haver no nível nacional. Exceto a hipótese de que no nível local possa-se construir um espaço público em que o exercício da cidadania ativa assumiria um papel preponderante de aprendizado. Assim, "o poder local configurarse-ia como um espaço privilegiado de se fazer avançar a democratização das políticas públicas de corte social, em um processo não-linear, mas que apontaria para a viabilidade de a descentralização levar à democratização, possibilitando o exercício do controle público e da participação ativa dos cidadãos na formulação e implementação das políticas setoriais" (Elias, 2000: 228).

O certo é que a descentralização coloca maiores exigências ao poder local, em relação ao financiamento dos serviços de saúde e aos modelos de atenção à saúde. Requer, na verdade, um grau mínimo de competência técnica, gerencial e política, como pré-requisitos para uma efetiva descentralização. Elias (2000: 222) sabe que "as autoridades locais nem sempre têm clareza sobre essas questões, e com freqüência o nível local pode estar sob o controle de oligarquias políticas".

Amorim e Perillo (2000), comentando a aprovação da Emenda Constitucional no 29 , em setembro de 2000 , que promove a vinculação de recursos para a saúde nos orçamentos das três esferas de governo, afirmaram: "o discurso oficial quer nos fazer acreditar que o aporte regular de recursos resultará na melhoria dos serviços de saúde aos cidadãos. Entretanto, chamamos a atenção para o risco de a emenda acabar se tornando inócua, pois o sistema público pode não conseguir oferecer melhores serviços à população, apesar de gastar mais. Por quê?".

a) privilegia-se a atenção à doença relativamente à promoção da saúde. Os serviços prestados são remunerados apenas quando existe a doença: o médico recebe por consulta, o laboratório pelo exame realizado, o hospital pela internação ou procedimentos praticados. Sem doença, não há pagamento pelo serviço prestado; e

b) poucos recursos são usados para prevenir e/ou promover a saúde: PAB e PSF. 
Além disso, Marques e Mendes (2000), a partir de um estudo recente do Centro de Estudos e Pesquisas de Administração Municipal (Cepam), mostraram que o nível inicial de gasto exigido pela Emenda Constitucional no 29, para o ano 2000 (7\%), já havia sido atingido pelos municípios paulistas em 1995 (13,8\%), enquanto o desejável para 2004 (15\%) havia sido superado em 1997 (16,2\%). Afirmaram, ainda, que essa realidade não era restrita aos municípios paulistas: de acordo com o Sistema de Informações sobre o Orçamento Público em Saúde (Siops), em levantamento realizado pelo Ministério da Saúde junto a 1.500 municípios, o percentual destinado à saúde havia sido de $15 \%$ das receitas de impostos e transferências constitucionais em 1998. Demonstram, assim, que a vinculação de recursos dificilmente irá alterar o quadro do financiamento das ações de saúde nos municípios. No caso dos Estados, considerando que a maioria deles vem destinando $6 \%$ de suas receitas de impostos e transferências constitucionais para a saúde, a Emenda Constitucional ampliou suas participações para $12 \%$. Contudo, os Estados tenderão a aplicar apenas o mínimo previsto pela lei.

Sinalizaram, então, que a Emenda Constitucional, por melhores que tenham sido as intenções de seus proponentes, apenas sancionou o comprometimento atual dos municípios e do governo federal. E, mediante uma elevação da participação dos Estados, abriu mão das contribuições sociais (como fonte de recursos para a saúde). Pela Emenda, ocorreria, na verdade, a completa desvinculação das contribuições sociais ao financiamento das ações de saúde, como se não houvesse disputa por esses recursos. ${ }^{36}$

Finalmente, deve-se enfatizar que a despeito de um esforço redistributivo da União, mantém-se um certo grau de desigualdade na alocação de recursos públicos para a saúde. De um lado, os Estados e municípios das regiões brasileiras detêm diferentes capacidades de arrecadação tributária e, portanto, diferentes volumes de recursos passíveis de serem aplicados em serviços de saúde. De outro lado, o principal mecanismo indutor para a fixação dos tetos financeiros das transferências federais continua sendo a série histórica, que reflete a capacidade instalada e a complexidade da rede. Como a distribuição da oferta de serviços, principalmente os de maior densidade tecnológica, é muito heterogênea, as regiões que concentram os serviços detêm os maiores valores. No entanto, a maior parcela da população que depende exclusivamente do SUS está localizada nas regiões mais pobres: Norte e Nordeste. Essa lógica tende a se repetir dentro dos Estados, privilegiando também os municípios mais ricos, gerando um ciclo vicioso.

A definição de um valor per capita único nacional parece ser insuficiente para reduzir essas distorções, uma vez que desconhece a capacidade instalada e o fluxo de usuários do SUS. A hierarquização da 
rede deve ser essencial para garantir um melhor aproveitamento dos

recursos tecnológicos, cada vez mais caros e complexos e, que não podem ser igualmente distribuídos entre os municípios e, algumas vezes, nem entre os Estados, como é o caso de certos tipos de transplantes ou serviços de alto custo/complexidade. ${ }^{37}$ Assim, a alocação de recursos financeiros de custeio, sem levar em conta a capacidade instalada da rede de serviços, pode levar a desperdícios, tais como o pagamento de medicamentos diretamente às farmácias, que cobram $40 \%$ acima do preço dos medicamentos adquiridos por compra direta.

Diante disso, apreende-se que reduzir as desigualdades regionais na oferta e acesso aos serviços constitui um dos maiores desafios colocados frente ao SUS. O caminho menos traumático para diminuir as desigualdades, porque atenuaria o conflito redistributivo, seria dar prioridade à diminuição das iniqüidades na alocação de recursos adicionais colocados à disposição do setor. Isto é, mediante a alocação de mais recursos e não com o estrangulamento dos mecanismos de financiamento das regiões com maior oferta de serviços. Senão, como fazer a transição? Como garantir que o aumento dos tetos não seja fruto de uma disputa entre os Estados? Como caminhar de um cenário a outro sem inviabilizar serviços necessários à população, sem deteriorar os serviços nas regiões que dispõem de melhor estrutura de oferta? ${ }^{38}$

A busca da eqüidade deveria passar, portanto, pelo incremento dos recursos para investimentos, balizados por um Plano Nacional de Prioridades de Investimentos, construído de forma ascendente, para viabilizar em cada Estado e município a infra-estrutura mínima necessária para atuar de acordo com sua realidade sanitária. ${ }^{39}$ Em um segundo momento, haveria uma redistribuição dos recursos de custeio, mediante um Plano Nacional de Saúde que utilizaria a capacidade instalada local e diminuiria o fluxo intermunicipal/interestadual de pacientes. A definição de diretrizes e prioridades de âmbito nacional — mediante pactos amplos sobre os critérios de alocação e as contrapartidas - eliminaria a necessidade de excessiva compartimentalização dos recursos. ${ }^{40}$

\section{Notas}

1 Este artigo constitui um fragmento de uma pesquisa mais ampla sobre as "Transferências federais negociadas de recursos para o Estado de São Paulo", coordenada por João Carlos Araújo e financiada pela Secretaria da Fazenda do Estado de São Paulo. Somos gratos a muitos pesquisadores da área da saúde, sem os quais este trabalho não teria sido 
possível. Em especial, gostaríamos de explicitar nossos agradecimentos a Maria Liz de Medeiros Roarelli, da Assessoria do Senado; Patrícia Lucchese, da Escola Nacional de Saúde Pública/Fundação Oswaldo Cruz; Áquilas Mendes, da Fundação Cepam-SP; Rosa Maria Marques, do Departamento de Economia da PUC-SP; José Rivaldo Melo de França, Deildes de Oliveira Prado e Karla Krepsky, do Ministério da Saúde; Márcia Tubone, da Secretaria de Saúde do Estado de São Paulo e Marta Arrecht, da Unesp. Evidentemente, as responsabilidades por eventuais equívocos que ainda persistirem são de responsabilidade dos autores.

2 Fundo de Saúde - conta especial em que são depositados e movimentados os recursos financeiros do SUS, sob fiscalização do Conselho de Saúde, nas três esferas de governo. A criação por meio de lei e o funcionamento do Fundo de Saúde representam um dos prérequisitos para que Estados, municípios e Distrito Federal recebam, de forma regular e automática, recursos federais do FNS para implementação de ações e serviços, alocandoos para investimentos e/ou assistência ambulatorial e hospitalar e demais ações de saúde.

3 Em 26 de janeiro de 2001, foi editada a Norma Operacional de Assistência à Saúde (NOAS-SUS 01/2001), que altera as formas de habilitação, sendo que os municípios teriam 30 dias a partir daquela data para se adequarem (Portaria no 94 do Ministério da Saúde). Os efeitos dessa Portaria não serão considerados nesse artigo, pois se privilegiou a estrutura existente até o ano de 2000.

${ }^{4}$ Cf. Elias (2000: 217): "o período aberto com a posse de Fernando Henrique Cardoso caracterizar-se-á pela promoção de alterações substantivas no processo de reformulação do sistema de saúde. Radicalizam-se algumas diretrizes e são introduzidas novas concepções."

5 No jargão da saúde pública, eqüidade, sinônimo de igualdade, assumiu o seguinte sentido: tratar desigualmente os desiguais, discriminar positivamente os que têm menos; ou simplesmente dar mais a quem tem menos (Mont'Alverne, 2000: 157).

6 Todas as figuras utilizadas neste trabalho a fim de facilitar a compreensão dos fluxos de recursos foram baseadas nas seguintes publicações do Ministério da Saúde: Ministério da Saúde (s/d) "Visão sistêmica do processo" e Mangueira et al. (1999).

7 Em agosto de 2000, o PSF cobria 53,9\% dos municípios brasileiros, correspondendo a $20,3 \%$ da população do país. O PACS atingia $82,6 \%$ dos municípios brasileiros, representando $49,9 \%$ da população do país. Destaca-se que esses programas priorizaram, em um primeiro momento, o atendimento da população de municípios com menor urbanização.

8 Os PACS e de PSFs foram adaptados para a área metropolitana da cidade de São Paulo, passando a ser chamados de Qualidade Integral à Saúde (Qualis). Já foi implementado em Itaquera, Vila Nova Cachoeirinha, Vila Brasilândia, Freguesia do Ó, Parque São Lucas e Sapopemba. São financiados com recursos do governo do Estado e não do governo federal. O critério de distribuição de recursos no Qualis passou a ser $\mathrm{R} \$ 63,60$ per capita por ano. Além dos serviços ambulatoriais e de laboratórios, incluem os serviços de saúde mental, bucal e parto. Incluem também programas de treinamento (educação continuada) às equipes. Na cidade de Niterói, foi implementado um programa semelhante, intitulado Programa Médico de Família, a partir da experiência cubana de medicina familiar.

9 O pagamento por procedimentos custeará as ações de média e alta complexidade executadas por Estados e municípios que assumirem a gestão plena do sistema.

${ }^{10}$ Cf. Costa, Silva e Ribeiro (1999: 51). Quando os municípios são enquadrados em quaisquer das modalidades de gestão definidas pela NOB 01/1996, os limites dos repasses federais ficam evidentes face às necessidades de financiamento do sistema local, o que pode gerar incentivos à contenção de custos, uso de recursos próprios e maior responsabilidade pela gestão dos mesmos.

${ }^{11}$ Essa estrutura dos tetos financeiros é definida de modo semelhante para todos os tipos de habilitação, seja municipal ou estadual. 
${ }^{12}$ O Fideps e o IVH-E estão condicionados aos critérios definidos em âmbito federal e à avaliação da CIB em cada Estado. Esse fator e índice integram o TFA do município e do respectivo Estado.

${ }^{13}$ Trata-se de um montante de recursos referente a procedimentos ambulatoriais de média complexidade, medicamentos excepcionais, órteses e próteses ambulatoriais e tratamento fora do domicílio. É transferido diretamente aos Estados e municípios habilitados.

${ }^{14}$ Consiste no pagamento dos valores apurados por intermédio do Sistema de Informações Ambulatoriais do SUS (SIA/SUS), com base na Autorização de Procedimentos de Alto Custo (Apac), documento que identifica cada paciente e assegura a prévia autorização e o registro adequado dos serviços que lhe foram prestados.

${ }^{15}$ Consiste no pagamento direto às Secretarias Estaduais de Saúde e às Secretarias Municipais de Saúde, pela execução de ações de média e alta complexidade de competência estadual e municipal contra a apresentação de demonstrativo de atividades realizadas ao Ministério da Saúde. Essas ações e o valor de sua remuneração são definidos em negociação na CIT e formalizados em portaria do órgão competente do Ministério (SVS/MS), previamente aprovadas no CNS.

${ }^{16}$ Consiste no pagamento direto às Secretarias Estaduais de Saúde e Secretarias Municipais de Saúde, pela prestação de serviços relacionados às ações de competência exclusiva da Secretaria de Vigilância Sanitária (SVS/MS), contra a apresentação de demonstrativo de atividades realizadas pela SES ao Ministério. Após negociação e aprovação na CIT e prévia aprovação no CNS, a SVS/MS publica a tabela de procedimentos do PDAVS e o valor de sua remuneração.

${ }^{17}$ A NOB 1/1996 não é explícita sobre a fórmula de cálculo do TFA.

${ }^{18}$ Segundo a NOB 01/1996, um determinado Estado se habilita à Gestão Avançada do Sistema Estadual se: "apresentar a programação pactuada e integrada ambulatorial, hospitalar e de alto custo, contendo a referência intermunicipal e os critérios para a sua elaboração; dispor de 60\% dos municípios do Estado habilitados nas condições de gestão estabelecidas nesta NOB, independente do seu contingente populacional; ou $40 \%$ dos municípios habilitados, desde que, nestes, residam $60 \%$ da população; ou ainda se dispor de $30 \%$ do valor do TFA, do Estado comprometido com transferências regulares e automáticas aos municípios".

${ }^{19}$ De acordo com a NOB 01/1996, um determinado Estado se habilita à Gestão Plena do Sistema Estadual se: "comprovar a operacionalização de mecanismos de controle da prestação de serviços ambulatoriais e hospitalares, tais como centrais de controle de leitos e internações, de procedimentos ambulatoriais e hospitalares de alto/culto e/ou complexidade e de marcação de consultas; dispor de $80 \%$ dos municípios do Estado habilitados nas condições de gestão estabelecidas nesta NOB, independente do seu contingente populacional; ou 50\% dos municípios habilitados, desde que, nestes, residam $80 \%$ da população; ou ainda se dispor de 50\% do valor do TFA, do Estado comprometido com transferências regulares e automáticas aos municípios".

${ }^{20}$ O Reforsus, pela sua importância dentro do Programa "Qualidade e Eficiência do SUS", merece alguns comentários. Trata-se de um projeto do Ministério da Saúde instituído no final de 1996, mediante um empréstimo celebrado entre o governo brasileiro, o Banco Interamericano de Desenvolvimento (BID) e o Banco Mundial (Bird), no valor de US\$ 650 milhões, que deve ser acrescido da contrapartida brasileira de US\$ 100 milhões. Tem como principal objetivo reforçar a rede de saúde com investimentos em projetos que visem à recuperação física, tecnológica, gerencial e operacional das unidades de saúde (públicas e filantrópicas) e, assim, ampliar o acesso da população aos serviços. O projeto possui dois componentes. No primeiro, estão, basicamente, os investimentos para recuperar a rede física de saúde (equipar hospitais, laboratórios, hemocentros etc.) e melhorar a atividade gerencial das unidades que receberem os recursos do 
projeto. No segundo componente, estão as ações, projetos e pesquisas para apoiar a melhoria do desempenho do sistema de saúde.

${ }^{21}$ Entre os 11 programas enumerados, seis (Melhoria Habitacional para o Controle da Doença de Chagas, Sistemas de Resíduos Sólidos, Serviços de Drenagem para o Controle da Malária, Melhorias Sanitárias Domiciliares, Sistemas de Abastecimento de Água, Sistemas de Esgotamento Sanitário) podem ser objeto de emendas parlamentares ao Orçamento da União.

${ }^{22}$ Cf. a lei no 8.080/1990, art. 36: "o processo de planejamento e orçamento do Sistema Único de Saúde, SUS, será ascendente, do nível local até o federal, ouvidos seus órgãos deliberativos, compatibilizando-se as necessidades da política de saúde com a disponibilidade de recursos em planos de saúde dos municípios, dos Estados, do Distrito Federal e da União". O § 1o estabelece que "os planos de saúde serão a base das atividades e programações de cada nível de direção do Sistema Único de Saúde, SUS, e seu financiamento será previsto na respectiva proposta orçamentária". De acordo com o § 20: "é vedada a transferência de recursos para o financiamento de ações não previstas nos planos de saúde, exceto em situações emergenciais ou de calamidade pública, na área de saúde".

${ }^{23}$ Em meados de agosto de 2000, foi aprovada a Emenda Constitucional que assegura um percentual mínimo de recursos da União, dos Estados e dos municípios a gastos na área de saúde. Gradualmente, Estados e municípios deverão alocar, no primeiro ano, pelo menos 7\% das receitas resultantes de impostos e transferências constitucionais para essa área, sendo que esse percentual crescerá gradualmente até atingir 12\% para os Estados e 15\% para os municípios, em 2004. A União deverá destinar 5\% a mais do que dispensou no ano 1999 à saúde; para os anos seguintes, o valor apurado no ano anterior deve ser corrigido pela variação nominal do PIB. Para uma estimativa dos possíveis impactos da Emenda Constitucional nf 29 nos gastos de saúde das três esferas de governo, ver Faveret, Oliveira, Krepsky, Malheiro, Benevides, (2000).

${ }^{24}$ Entre 1996 e 1998, a CPMF era destinada exclusivamente ao financiamento da saúde. Quando foi reaprovada, em 1999, a alíquota de contribuição passou de 0,20\% para $0,38 \%$, ficando $0,20 \%$ para a saúde e $0,18 \%$ para a Previdência.

${ }^{25}$ Em março de 1999, o PAB garantia um mínimo de R \$10,00 e um máximo de R \$ 18,00 per capita/ano para os municípios investirem em atendimento básico em saúde.

${ }^{26}$ Portaria no 1.884/GM, de 18 de dezembro de 1997, do Ministério da Saúde, no art. 1o, define que "são repassados mensalmente para os municípios habilitados na gestão plena da atenção básica recursos equivalentes a 1/12 de $\mathrm{R} \$ 10,00$ por habitante/ano (parte fixa do PAB)". No art. 40, estabelece que "para os municípios não habilitados, no prazo máximo de 60 (sessenta) dias a contar da data da publicação desta portaria, o repasse será efetuado por produção de serviços e o valor total repassado terá como limite máximo a média de seu faturamento em assistência básica no ano de 1996".

${ }^{27}$ Inclui o PACS e o PSF. No primeiro, são repassados recursos no valor de R $\$ 2.200,00 /$ ano para cada agente comunitário de saúde até um limite de $30 \%$ do valor fixo do PAB. No segundo, são repassados recursos no valor de $\mathrm{R} \$ 28.000$,00/ano para cada equipe de saúde instalada. Nos dois casos, trata-se de recursos destinados ao pagamento de salários e encargos dos profissionais específicos ao desenvolvimento do programa.

${ }^{28}$ A portaria no 2.409/1998, do Ministério da Saúde, definiu critérios para repasse de recursos financeiros destinados ao combate das carências nutricionais nos municípios. Os recursos transferidos a cada município pelo Programa de Combate às Carências Nutricionais básicas correspondem a um máximo de 50\% dos custos para as atividades de recuperação nutricional, que incluem, prioritariamente, o aleitamento materno e o combate às deficiências de ferro (gestantes e crianças) e de vitaminas A (menores de 5 anos). 
${ }^{29}$ A portaria no 2.283/1998, do Ministério da Saúde, instituiu critérios para repasse de recursos financeiros destinados às Ações Básicas de Vigilância Sanitária.

${ }^{30}$ Deve-se enfatizar que apenas $10 \%$ dos municípios brasileiros assumiram a gestão plena do sistema. Evidentemente, isso tem implicações sobre o montante repassado fundo a fundo e/ou mediante pagamentos federais por produção de serviços. Diante disso, vai consolidando-se a necessidade de que os Estados federados desempenhem um papel mais atuante no planejamento e na coordenação do sistema. O que exige investimentos e, portanto, capacidade de alocação de recursos. Porém, como os recursos provinham predominantemente das transferências federais, diretamente ao produtor de serviços ou aos municípios, o planejamento estadual ficava dificultado. (Essa situação tenderá a se modificar com a implementação da Emenda Constitucional, no 29, como será visto mais à frente.)

${ }^{31}$ Cf. Mendes et al. (1999: 99), o Tesouro do Estado de São Paulo respondeu por 59,3\% do gasto público total com saúde e os recursos vinculados federais representaram apenas $6 \%$.

${ }^{32}$ Deve-se esclarecer que a nova administração da prefeitura de São Paulo, encabeçada por Marta Suplicy, efetuou os procedimentos para a habilitação do seu sistema de saúde na Gestão Plena da Atenção Básica.

${ }^{33}$ Porém, deve-se salientar que a partir de 1995, houve uma reorganização da Secretaria da Saúde do Estado de São Paulo a fim de atender ao papel de gestor estadual que lhe conferia a política do SUS. Nesse momento, foi alterado o processo de regionalização da Secretaria Estadual de Saúde, de forma que os 62 Escritórios Regionais de Saúde (Ersas), criados em 1986, foram substituídos por 24 Direções Regionais de Saúde (DRS), de acordo com os decretos nf 40.082 e no 40.083 , de 15 de maio de 1995. Com isso, esperava criar melhores condições para o planejamento regional da saúde no Estado de São Paulo (Cf. Mendes et al., 1999: 21).

${ }^{34}$ Em procedimentos de elevada complexidade, parte dos recursos não é transferida, mas tem seus pagamentos realizados diretamente por meio do FAEC. Essa rubrica inclui também recursos destinados a compensar a utilização da rede de serviços de saúde do Estado de São Paulo por pacientes de outros Estados.

${ }^{35}$ No mesmo sentido, ver Instituto de Saúde (2001: 28-29): "Na prática, segundo declaração conjunta do Conselho Nacional de Secretários Estaduais de Saúde, CONASS e Conselho Nacional de Secretários Municipais de Saúde, CONASEMS, o Ministério acabou segmentando o Teto Financeiro da Assistência, concebido na NOB 01/96 como único para o custeio da assistência à saúde em vários sub-tetos, definidos e gerenciados pelo governo federal. Esses sub-tetos são definidos como estímulos para que Estados e municípios implementem programas e serviços específicos, e não podem ser redirecionados para outras atividades, mesmo que eventualmente ocorra saldo em um determinado item de despesa e falte em outro."

${ }^{36}$ Além disso, a Emenda desencadeou uma discussão sobre se o seu pouco preciso conceito de gastos com saúde inclui ou não saneamento, limpeza urbana, tratamento de resíduos sólidos etc.

${ }^{37}$ Para uma avaliação dos consórcios intermunicipais de saúde, ver Ribeiro e Costa (2000). Ver também Dain (2000), que chama a atenção para o crescimento exagerado do número de municípios na década de 90, o que pode implicar uma excessiva pulverização dos recursos, se não ocorrer uma hierarquização/regionalização do atendimento e, portanto, da rede de serviços.

${ }^{38}$ Uma equipe de pesquisadores da Fiocruz — Patrícia Tavares Ribeiro Lucchese (coordenadora), Luciana Tricai Cavallini, Mônica Rodrigues Campos e Márcia Garcia - está procurando desenvolver uma metodologia que possibilite caracterizar as diferenças 
regionais na gestão pública do cuidado à saúde a fim de subsidiar as negociações na CIT e viabilizar uma redução das desigualdades na alocação dos recursos do SUS (Projeto "Processo Alocativo e Redução de Desigualdades Regionais: Eqüidade na Gestão do Sistema Único de Saúde" — DCS/ENSP — SE/Ministério da Saúde — Abrasco).

${ }^{39}$ O Ministério da Saúde patrocinou a elaboração de uma pesquisa em diversos campos de interesses da saúde, com destaque para as indústrias de equipamentos hospitalares e de medicamentos. Ver Braga e Silva (2001).

${ }^{40}$ O governo do Estado do Rio Grande do Sul instituiu a Municipalização Solidária da Saúde, como forma de cooperação técnica e financeira com todos os municípios em alguma forma de gestão do SUS, para ampliação e qualificação da atenção à saúde prestada à população (Ferla e Martins Jr., 2000: 187). Mediante a Portaria SES/RS no 19, de 5 de junho de 2000, definiu os seguintes critérios para cálculo dos valores a serem repassados trimestralmente aos municípios gaúchos: Coeficiente de População Total do Município, Coeficiente de População com Idade Menor de 14 anos, Coeficiente de População com Idade Maior de 60 anos, Coeficiente do Inverso da Capacidade Instalada Municipal, Coeficiente Ponderado de Mortalidade Infantil do Município, Prioridade Regional (ordem de prioridade dada à saúde pela população de cada município nas assembléias do Orçamento Participativo Estadual), Coeficiente do Inverso da Arrecadação per capita Municipal e o Coeficiente do Volume de Recursos Utilizados na Área da Saúde. Com esses critérios, estão sendo beneficiados principalmente os menores e mais carentes municípios gaúchos. Deve-se salientar ainda que os recursos são transferidos do Fundo Estadual de Saúde para os Fundos Municipais de Saúde, sem qualquer prescrição. Cada município tem autonomia para decidir em que irá gastar os recursos, dentro da função saúde, desde que sua aplicação seja aprovada pelos respectivos Conselhos Municipais de Saúde. Ver, Secretaria da Saúde do Estado do Rio Grande do Sul. (2000), SUS é legal: legislação federal e estadual do SUS. Porto Alegre.

\section{Referências bibliográficas}

Amorim, Maria Cristina S.; Perillo, Eduardo B. F. (2000), "Os velhos e tortuosos caminhos da saúde". Gazeta Mercantil, São Paulo, 3 de agosto, p. A-3.

Arretche, Marta; Rodriguez, Vicente. (1999), "Descentralizar e universalizar a atenção à saúde", in Arretche, Marta ; Rodriguez, Vicente. (org.), Descentralização das políticas sociais no Brasil. São Paulo: Edições Fundap: Fapesp/Brasília, DF: Ipea, p. 126-158.

Arretche, Marta; Marques, Eduardo. (2000), "Municipalização da saúde no Brasil: diferenças regionais, poder de voto e estratégias de governo". Revista da Organização Pan-americana de Saúde (no prelo).

Baer, Werner; Campino, Antonio Carlos; Cavalcanti, Tiago. (2000), "Condições e política de saúde no Brasil: uma avaliação das últimas décadas". Revista Economia Aplicada, vol. 4, re 4. São Paulo: Departamento de Economia da Faculdade de Economia, Administração e Contabilidade da USP e da Fundação Instituto de Pesquisas Econômicas (FIPE), p. 763-785. 
Braga, José Carlos de Souza; Silva, Pedro Luiz Barros. (2001), "A mercantilização admissível e as políticas públicas inadiáveis: estrutura e dinâmica do setor saúde no Brasil", in Negri, Barjas; Giovanni, Geraldo. (org.), Brasil: radiografia da saúde. Campinas: Instituto de Economia/Núcleo de Estudos de Políticas Públicas/ Brasília, DF: Ministério da Saúde, p. 19-42.

Caleman, Gilson; Duarte, José Ênio Servilha. (2000), "Gestão de recursos: atendendo as necessidades sociais e avaliando resultados". Caderno da $11^{a}$ Conferência Nacional de Saúde. Brasília, DF, 15 a 19 de dezembro, p. 197-213.

Capristrano Filho, David. (1999), "O programa de saúde da família em São Paulo". Estudos Avançados, no 35. São Paulo: Instituto de Estudos Avançados/USP, p. 89-100.

Cohn, Amélia; Eutas, Paulo E. (coord.), O público e o privado na saúde: o PAS em São Paulo. São Paulo: Editora Cortez/Cedec.

Costa, Nilson do Rosário; Silva, Pedro Luís Barros; Ribeiro, José Mendes. (2000), "A descentralização do sistema de saúde no Brasil". Revista do Serviço Público, ano 50, no 3. Brasília, DF: Fundação Escola Nacional de Administração Pública, p. 33-56.

DAIN, Sulamis. (2000), Do direito social à mercadoria. Rio de Janeiro: Instituto de Medicina Social/UERJ (Tese de Professor Titular).

Elıas, Paulo Eduardo. (2000), "Relações de responsabilidade entre os gestores do SUS: perspectivas para a garantia do acesso, qualidade e humanização da atenção". Caderno da 11 a Conferência Nacional de Saúde. Brasília, DF, 15 a 19 de dezembro, p. 215-231.

Elias, Paulo Eduardo. (1996), "Estrutura e organização da atenção à saúde no Brasil", in Coнn, Amélia; Elias, Paulo E., Saúde no Brasil: políticas e organização de serviços. 3a Edição Revista e Ampliada. São Paulo: Editora Cortez/Cedec, 1999, p. 59- 119.

Faveret, Ana Cecília de Sá Campello; Oliveira, Fabrício Augusto de; Krepsky, Karla; M alheiro, Paulo César da Fonseca; Benevides, Rodrigo Pucci de Sá e. (2000), Estimativas de impacto da vinculação constitucional de recursos para a saúde (Emenda Constitucional, no 29/00). Brasília, DF: SIOPS/DPI/SIS/Ministério da Saúde (mimeo).

FerLa, Alcindo Antonio; M artins JR. Fernando. (2000), "Remuneração dos prestadores diretos de ações e serviços de saúde: do financiamento de interesses privados à garantia de qualidade, acesso e humanização". Caderno da $11^{1}$ a Conferência Nacional de Saúde. Brasília, DF, 15 a 19 de dezembro, p. 169-196.

Fundação Nacional de Saúde. (2000), Convênios - Projetos Passíveis de Aplicação de Recursos. Brasília, DF: Ministério da Saúde (http://www.funasa.gov.br/conv/criter/ criter02.htm).

Goulart, Flavio A. de Andrade. (s/d), Política de saúde contemporânea no Brasil: o SUS. Texto preparado para a Disciplina Saúde no Brasil: situação atual e perspectivas. Brasília, DF (http://www.universidadevirtual.br).

Jatene, Adib. (1999), "Novo modelo de saúde". Estudos Avançados, no 35. São Paulo: Instituto de Estudos Avançados/USP, p. 51-64.

Heimann, Luiza S; et al. (2000), Descentralização do Sistema Único de Saúde: trilhando a autonomia municipal. São Paulo: Editora Hucitec/Sociedade Brasileira de Vigilância de Medicamentos.

Instituto de SAúde. (2001), Financiamento de saúde e eqüidade. São Paulo: Instituto de Saúde/Secretaria Estadual de Saúde do Estado de São Paulo (Projeto "O financiamento do sistema de saúde no Brasil e a busca da eqüidade").

Lucchese, Patrícia T.R. (1996), "Descentralização do financiamento e gestão da assistência à saúde no Brasil: a implementação do Sistema Único de Saúde — retrospectiva 1990/ 1995". Planejamento e Políticas Públicas, no 14. Brasília, DF: IPEA, p. 75-156.

Oliveira JR., Mozart de. (2000), "Critérios para repasse dos recursos federais: papel redistributivo do governo federal (MS) e estadual no financiamento da saúde". Caderno da 11 a Conferência Nacional de Saúde. Brasília, DF, 15 a 19 de dezembro, p. 139-167. 
M angueira, José Antônio Bonfim; Carneiro, Jozimar Barros; Aguila, Maria Sandra Barbosa Del; Bernardino, Vera Lúcia Dalla; Prado, Deildes de Oliveira; Almeida, Haley. (1999), Orientações sobre aplicação de recursos financeiros do SUS, repassados fundo a fundo. Brasília, DF: Ministério da Saúde/Secretaria Executiva/Departamento de Controle, Avaliação e Auditoria/Coordenação Geral de Análise da Gestão/Coordenação de Controle das Ações de Saúde (http://sna.saude.gov.br).

Marques, Rosa Maria; Mendes, Áquilas. (1999), "O financiamento do sistema público de saúde brasileiro". Serie Financiamiento del desarrollo, n- 82. Santiago: CEPAL (Projeto CEPAL/GTZ - Reformas de los sistemas de salud en América Latina).

M Arques, Rosa Maria; Mendes, Áquilas. (2000a), "Novas incertezas sobre o financiamento da saúde". Gazeta Mercantil, São Paulo, 13 de setembro, p. A-3.

M ARques, Rosa Maria; Mendes, Áquilas. (2000b), "O financiamento da atenção à saúde no Brasil". Caderno da 11 a Conferência Nacional de Saúde. Brasília, DF, 15 a 19 de dezembro, p. 118-138.

M Aтtos, Marluza. (2000), "Senado aprova emenda que dá à Saúde mais R 7 bilhões por ano". Valor Econômico. São Paulo, 11 de agosto, p. A-8.

Mendes, Áquilas; Marques, Rosa Maria. (1999), Financiamento: a doença crônica da saúde pública brasileira. Anais do V Encontro Nacional de Economia da Saúde, promovido pela Associação Brasileira de Economia da Saúde (ABRES) e pelo Instituto de Saúde Coletiva da Universidade Federal da Bahia, Salvador, 29 e 30 de novembro.

Mendes, Áquilas; M Arques, Rosa Maria; Leite, Marcel Guedes; Tubone, Márcia. (1999), Financiamento da saúde: análise dos gastos estaduais e municipais (Estado de São Paulo). Brasília, DF: IPEA (Relatório de Pesquisa, Projeto BRA 97/03).

Ministério dA SAÚdE. (2000a), "Legislação básica do SUS". 11 a Conferência Nacional de Saúde, 15 a 19 de dezembro, Brasília, DF.

Ministérioda SAÚde. (2000b), Normas de financiamento de programas e projetos mediante a celebração de convênios. Orientações Técnicas. Brasília, DF: Fundo Nacional de Saúde. Edição Revisada (http://www.saude.gov.br).

Ministério da SAÚdE. (1998), Instrução Normativa $n ²$ 01/98. Brasília, DF, 2 de janeiro (http://www.saude.gov.br).

Ministério da SAÚde. (s/d), Visão sistêmica do processo. Brasília, DF: Fundo Nacional de Saúde/Secretaria-Executiva/Ministério da Saúde.

Ministério da SAÚde. (1997), Norma Operacional Básica do Sistema Único de Saúde SUS (NOB-SUS-1996). Brasília, DF (Publicada no D.O.U. de 6.11.1996 - http:// www.saude.gov.br).

Ministério da SAúde. (1997), Portaria n-1882/GM, de 18 de dezembro de 1997. Brasília, D.F. (http://www.saude.gov.br).

Ministério da SAúde. (1996), Reforço à Reorganização do Sistema Único de Saúde Reforsus. Brasília, DF: Secretaria-Executiva/Assessoria de Comunicação Social.

Piola, Sérgio Francisco; Ribeiro, José Aparecido Carlos; Reis, Carlos Octávio Ocké. (1999), Financiamento da saúde: o que mudou com a CPMF. Brasília, DF: Ipea (mimeo).

Piola, Sérgio Francisco; Biasoto JR., Geraldo. (2001), "Financiamento do SUS nos anos 90", in NeGRI, Barjas; GiovanNI, Geraldo. (org.), Brasil: radiografia da saúde. Campinas: Instituto de Economia/Núcleo de Estudos de Políticas Públicas/ Brasília, DF: Ministério da Saúde, p. 219-232.

Prado, Sérgio; Cavalcanti, Carlos Eduardo. (1999), Análise do sistema de partilha de recursos da federação brasileira. São Paulo: Fundap/Brasília, DF: Ipea.

Ribeiro, José Mendes; Costa, Nilson do Rosário. (2000), "Regionalização da assistência à saúde no Brasil: os consórcios municipais no Sistema Único de Saúde (SUS)". Revista Planejamento e Políticas Públicas, no 22. Brasília, DF: Ipea, p. 173-220. 
Roarelli, Maria Liz de Medeiros. (s/d), Análise das transferências negociadas: por órgão e esfera de governo, ano de 1992.

Secretaria da Saúde do Estado do Rio Grande do Sul. (2000), SUS é legal: legislação federal e estadual do SUS. Porto Alegre.

SerRA, José. (2000), "Saúde: a vinculação necessária". Folha de São Paulo, São Paulo, 9 de julho, p. A-3.

SERRA, José. (1999), "A questão da saúde no Brasil". Estudos Avançados, no 35. São Paulo: Instituto de Estudos Avançados/USP, p. 39-50.

SerRA, José; Afonso, José Roberto R. (1999), "Federalismo fiscal à brasileira: algumas reflexões". Revista do BNDES, vol. 6, no 12. Rio de Janeiro: BNDES, p. 3-30.

Teixeira, Suely C. S.; Monteiro, Valéria de O.; Miranda, Verônica A. (1999), "Programa médico de família no município de Niterói". Estudos Avançados, no 35. São Paulo: Instituto de Estudos Avançados/USP, p. 147-155.

Tribunal de Contas da União. (2000), Convênios - Principais Informações para Estados e Municípios. Brasília, DF: Secretaria-Geral de Controle Externo, janeiro.

Yunes, João. (1999), "O SUS na lógica da descentralização". Estudos Avançados, no 35 . São Paulo: Instituto de Estudos Avançados/USP, p. 65-70. 


\section{Resumo \\ Resumen \\ Abstract}

\section{Transferências da União em saúde para o Estado de São Paulo \\ Marcos Antonio Macedo Cintra e João Carlos Araújo}

A partir da análise da legislação básica do Sistema Único de Saúde (SUS) procura-se apreender os mecanismos de repasse de recursos federais para as instâncias subnacionais de governo, a institucionalidade da programação e da negociação, bem como os principais programas. Busca-se, ainda, identificar as principais fontes orçamentárias de recursos federais e os critérios de distribuição desses recursos nos diferentes programas. Finalmente, desenvolve-se uma tentativa de quantificar a participação do Estado de São Paulo no volume de transferências federais na área da saúde.

\section{Transferencias de la Unión en salud para el Estado de São Paulo \\ Marcos Antonio Macedo Cintra y João Carlos Araújo}

A partir del análisis de la legislación básica del Sistema Único de Saúde (SUS) (Sistema Único de Salud) procurase aprehender los mecanismos de repaso de recursos federales para las instancias subnacionales del gobierno, la institucionalidad de la programación y de la negociación, así como los principales programas. Buscase todavía identificar las principales fuentes presupuestarias de recursos federales y los criterios de distribución de esos recursos en los diferentes programas. Finalmente, desarrollase una tentativa de medir la participación del Estado de São Paulo en el volumen de transferencias federales en el área de la salud.

\section{Transferring health federal funds to the state of São Paulo \\ Marcos Antonio Macedo Cintra and João Carlos Araújo}

Based on an analysis of SUS (acronym of Sistema Único de Saúde/Single Health System) general regulations the author makes an attempt to clarify mechanisms for distribution of federal funds to states and municipalities, its scheduling and negotiations as well as its major programs. It is also an attempt to identify budget sources of federal funds, criteria for distribution of funds to different programs and finally quantify the share of the State of São Paulo in the total volume of federal transfers to health system.

\section{RSP}

Revista do

Serviço

Público

Ano 52

Número 3

Jul-Set 2001

Marcos Antonio

Macedo Cintra

e João Carlos

Araújo são

pesquisadores da

Diretoria de

Economia do

Setor Público da

Fundação do

Desenvolvimento

Administrativo

do Estado de

São Paulo

(Fundap). 
A Revista do Serviço Público é uma publicação da ENAP Escola Nacional de Administração Pública, voltada para a divulgação e debate de temas relacionados ao Estado, à administração pública e à gestão governamental. Procurando o aprimoramento permanente da revista, tanto no seu conteúdo quanto na apresentação gráfica, pedimos aos nossos colaboradores a observação das normas abaixo descritas.

\section{Normas para os colaboradores}

1. Os artigos, sempre inéditos no Brasil, devem conter em torno de 25 laudas de 20 linhas de 70 toques.

2. Os originais devem ser encaminhados ao editor, em arquivo digital, em programa de uso universal e enviados para editora@enap.gov.br . Usar apenas as formatações-padrão.

3. Cada artigo deve vir acompanhado de um resumo analítico em português, espanhol e inglês, de cerca de 150 palavras, que permita uma visão global e antecipada do assunto tratado.

4. Na primeira página do artigo, deve constar informação sobre formação e vinculação institucional do autor (em até duas linhas).

5. Notas, referências e bibliografia devem vir ao final do artigo, e não ao pé da página. Notas e referências, sendo o caso, devem vir devidamente numeradas.

6. Além de artigos, a revista receberá comunicações, notas informativas, notícias e relatórios conclusivos de pesquisas em desenvolvimento, com até 15 laudas. Resenhas de livros, em torno de 4 laudas, devem conter uma apresentação sucinta da obra e eventuais comentários que situem o leitor na discussão.

7. Os trabalhos que se adequarem à linha temática da revista serão apreciados pelo conselho editorial, que decidirá sobre a publicação com base em pareceres de consultores ad hoc.

8. Os originais enviados à Revista do Serviço Público não serão devolvidos. A revista compromete-se a informar os autores sobre a publicação ou não de seus trabalhos.

\section{Convite a resenhadores}

A Revista do Serviço Público convida todos os interessados em remeter resenhas de trabalhos publicados no Brasil e no exterior sobre Estado, administração pública e gestão governamental.

As resenhas devem ser originais e não exceder a cinco laudas datilografadas em espaço duplo com 20 linhas de 70 toques, e devem apresentar de modo sucinto a obra, com comentários que situem o leitor na discussão apresentada.

As resenhas devem ser enviadas em português, sem notas de rodapé, contendo o título completo e subtítulo do livro, nome completo do autor, local de publicação, editora e ano de publicação, bem como uma breve informação sobre a formação e vinculação institucional do resenhador (em até duas linhas), acompanhadas do respectivo disquete.

\section{Nota aos editores}

Pedimos encaminhar à Revista do Serviço Público exemplares de livros publicados, a fim de serem resenhados. Os resenhadores interessados receberão cópias dos livros enviados. 